\title{
Seipin deficiency increases chromocenter fragmentation and disrupts acrosome formation leading to male infertility
}

\author{
AE El Zowalaty ${ }^{1,2}$, C Baumann ${ }^{1}, \mathrm{R} \mathrm{Li}^{1,2}, \mathrm{~W} \mathrm{Chen}^{3}$, R De La Fuente ${ }^{1}$ and $\mathrm{X} \mathrm{Ye}^{\star, 1,2}$
}

The Berardinelli-Seip congenital lipodystrophy type 2 (Bscl2, seipin) gene is involved in adipogenesis. Bscl2 ${ }^{-1-}$ males were infertile but had normal mating behavior. Both $B s c / 2^{-1-}$ cauda epididymis sperm count and sperm motility were $\sim 20 \times$ less than control. Bsc/2 ${ }^{-1-}$ seminiferous tubules had relatively normal presence of spermatogonia and spermatocytes but had reduced spermatids and sperm. Spatiotemporal expression analyses in Bscl2 ${ }^{+/+}$testes demonstrated prominent Bscl2 transcriptional activity in spermatocytes with a plateau reached around postnatal day 28. Seipin protein localization was most abundant in postmeiotic spermatids, suggesting translational repression of Bsc/2 mRNA in spermatocytes. In situ end-labeling plus detected increased spermatid apoptosis in Bscl2 ${ }^{-I-}$ testis and annexin $\mathrm{V}$ detected increased percentage of positive $B s c / 2^{-1-}$ round spermatids compared with control. Immunofluorescence of marker proteins synaptonemal complex proteins 3 and 1 (SYCP3 and SYCP1), and H3K9me3 (histone H3 trimethylated at lysine 9) in germ cell spreads detected normal meiotic chromosome pairing and homologous chromosome synapsis in Bscl2 ${ }^{-1-}$ spermatocytes, but significantly increased percentages of round spermatids with chromocenter fragmentation and late spermatids and sperm with chromatin vacuoles, indicating defective chromatin condensation in Bscl2 ${ }^{-1-}$ spermatids. Bscl2 ${ }^{l-}$ late spermatids were disorganized within the seminiferous epithelium, despite normal appearance of Sertoli cells detected by vimentin immunofluorescence. Peanut agglutinin staining revealed various abnormalities of acrosomes in Bscl2 ${ }^{-1-}$ late spermatids, including the absence, irregular-shaped, and fragmented acrosomes, indicating defective acrosome formation in $\mathrm{Bscl}^{-1-}$ late spermatids, which may affect late spermatid orientation in the seminiferous epithelium. Mitotracker strongly stained the midpiece of control sperm but only very weakly labeled the midpiece of $B s c / 2^{-I-}$ sperm, indicating defective mitochondrial activity that most likely contributed to reduced $B s c / 2^{-I-}$ sperm motility. These data demonstrate novel roles of seipin in spermatid chromatin integrity, acrosome formation, and mitochondrial activity. Increased spermatid apoptosis, increased chromocenter fragmentation, defective chromatin condensation, abnormal acrosome formation, and defective mitochondrial activity contributed to decreased sperm production and defective sperm that resulted in Bscl2 ${ }^{\prime-}$ male infertility.

Cell Death and Disease (2015) 6, e1817; doi:10.1038/cddis.2015.188; published online 16 July 2015

Berardinelli-Seip congenital lipodystrophy type 2 (BSCL2) gene encodes the protein seipin. ${ }^{1}$ Mutations of BSCL2 are associated with generalized lipodystrophy characterized by a near-complete absence of adipose tissue and early-onset metabolic complications, such as insulin resistance and diabetes. ${ }^{1-3}$ Seipin is an integral endoplasmic reticulum (ER) membrane protein with two transmembrane domains, cytosolic N- and C-termini, and a central loop domain in the ER lumen. ${ }^{4,5}$ Various adipocyte-associated functions of seipin have been proposed. It is found at ER lipid droplet junctions that are important for droplet morphology in yeast. ${ }^{6}$ In Drosophila, it has been shown to promote adipose tissue fat storage via physical interactions with SERCA (sarco/ER $\mathrm{Ca}^{2+}$-ATPase), which is an ER calcium pump solely responsible for transporting cytosolic calcium into the ER lumen. ${ }^{7}$ Seipin is also reported to regulate cyclic AMP/protein kinase A-mediated lipolysis that is essential for adipocyte maturation. $^{8}$

Besides adipose tissue, seipin is also highly expressed in the testis. ${ }^{1,9,10}$ It was noticed that $B s c l 2^{-1}$ males were infertile during previous study of seipin deficiency in adipose tissue loss and metabolic disorders. ${ }^{8}$ A recent study demonstrated that BSCL2 mutations in a man and seipin deficiency in mice led to teratozoospermia and male infertility due to impaired testicular phospholipid homeostasis. ${ }^{10}$

Bscl2/seipin has been predominantly recognized for its role in adipogenesis ${ }^{11,12}$ and phospholipid homeostasis. ${ }^{10}$ However, other potential roles, such as germ cell apoptosis

\footnotetext{
${ }^{1}$ Department of Physiology and Pharmacology, College of Veterinary Medicine, University of Georgia, Athens, GA, USA; ${ }^{2}$ Interdisciplinary Toxicology Program, University of Georgia, Athens, GA, USA and ${ }^{3}$ Department of Physiology, Georgia Regents University, Augusta, GA, USA

*Corresponding author: X Ye, Department of Physiology and Pharmacology, College of Veterinary Medicine; Interdisciplinary Toxicology Program, University of Georgia, 501 DW Brooks Drive, Athens, GA 30602, USA. Tel: +1 706542 6745; Fax: +1 706542 3015; E-mail: ye@uga.edu

Abbreviations: ATR, Rad3-related protein; Bscl2, seipin, Berardinelli-Seip congenital lipodystrophy type 2; DAPI, 4',6-diamino-2-phenylindole; ER, endoplasmic reticulum; H3K9me3, histone $\mathrm{H} 3$ trimethylated at lysine 9; HRP, horseradish peroxidase; ISEL ${ }^{+}$, in situ end-labeling plus; mES, mouse embryonic stem; PA-PLA, phosphatidic acid-preferring phospholipase $\mathrm{A}_{1}$; PNA, peanut agglutinin; PND, postnatal day; PRM1/2, protamines 1 and 2; SERCA, sarco/ER Ca ${ }^{2+}$-ATPase; SSC, salinesodium citrate; SYCP $1 / 3$, synaptonemal complex proteins 1 and 3

Received 09.3.15; revised 03.6.15; accepted 04.6.15; Edited by E Baehrecke
} 
and maintenance of DNA integrity, have been largely unexplored. Male germ cell apoptosis is a physiological process that maintains homeostasis in the seminiferous tubules during spermatogenesis. An early wave of male germ cell apoptosis occurs during prepubertal development and is thought to keep a proper balance between germ cells and supporting Sertoli cells. ${ }^{13}$ Germ cell apoptosis also occurs in seminiferous tubules of adult males ${ }^{14}$ and it is estimated that $\sim 75 \%$ of all male germ cells produced are discarded through apoptosis as a mechanism to remove aberrant and excess germ cells. ${ }^{15}$ Interestingly, Bscl2 was shown through transcription profiling of mouse embryonic stem (mES) cells to be transcriptionally activated on exposure to a broad spectrum of genotoxic compounds. ${ }^{16}$ This transcriptional activation of Bscl2 was associated with inhibition of DNA replication and activation of the ataxia telangiectasia and Rad3-related protein (ATR) signaling pathway, ${ }^{17}$ suggesting that seipin might be involved in maintaining DNA integrity.

We aim to determine the role of seipin in male fertility using our $\mathrm{BsCl}^{-1-}$ mouse model. ${ }^{8}$ Here we show that seipin deficiency disrupts spermatid DNA integrity, increases spermatid apoptosis, and interferes with acrosome formation.

\section{Results}

$\mathrm{Bscl}^{-1-}$ male infertility due to reduced sperm production and impaired sperm motility. Two months of mating study revealed that all $\mathrm{Bscl}^{+/+}$females $(N=7)$ mated with $\mathrm{Bscl} 2^{+/+}$ males $(100 \%)$ were pregnant. The average number of litters was $2.3 \pm 0.48(N=7)$ and the average litter size was $8.8 \pm 3.0(N=16$ litters $)$. However, none of the $B s c l 2^{+/+}$ females $(N=10)$ mated with $B s c l 2^{-1-}$ males $(N=10)$ became pregnant $(0 \%)$, demonstrating that $\mathrm{Bscl}^{-1-}$ males were infertile (Figure 1a). These $B s c / 2^{-1}$ males had normal mating activities indicated by comparable plugging rate and plugging latency with $\mathrm{Bscl}^{+/+}$males (Figures $1 \mathrm{a}$ and $\mathrm{b}$ ).

At the end of the fertility test, there were $9.3 \%$ reduction of body weight and $14.3 \%$ reduction of testis weight in $\mathrm{Bscl}^{-1-}$ males (Figures 1c and d). There was no significant difference
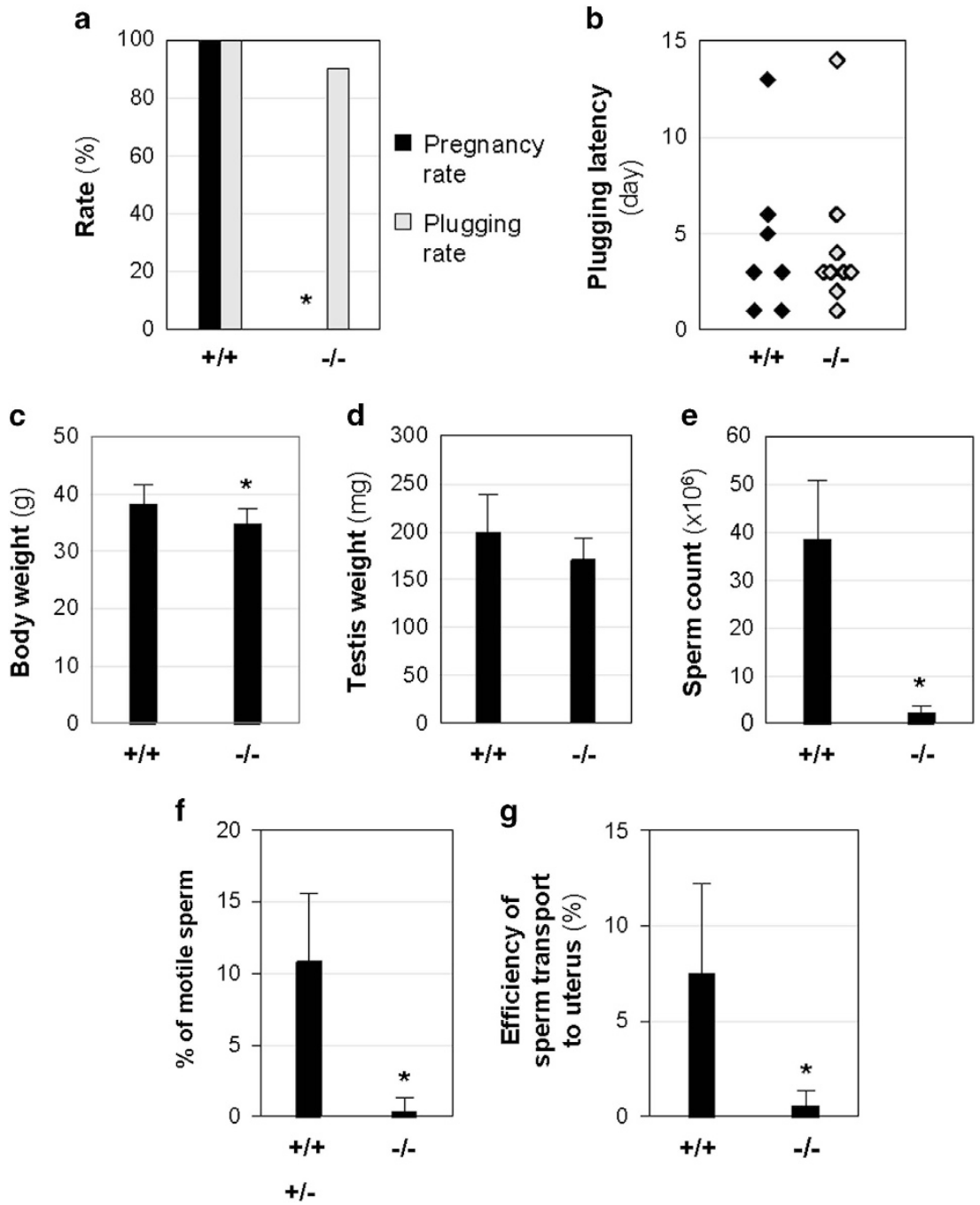

Figure 1 Male fertility test and sperm analyses. $+/+, B s c / 2^{+/+} ;+/-, B s c / 2^{+/-} ;-/-, B s c / 2^{-/-}$. (a) Pregnancy rate and plugging rate from 2 months of fertility test. (b) Plugging latency. (c) Body weight. (d) Testis weight. (e) Sperm count from cauda epididymis. (a-e): $N=7(+/+)$ and $10(-/-)$. (f) Percentage of motile sperm. $N=6$ $(+/+$ and $+/-)$ and $9(-/-)$. (g) Efficiency of sperm transport to the uterus. $N=5(+/+)$ and $7(-/-)$. Error bar, S.D.; ${ }^{*} P<0.05$ 
in the relative testis weight (Supplementary Figure S1A). However, Bscl2 ${ }^{-1}$ cauda epididymis sperm count was only $\sim 5.4 \%$ of that from $\mathrm{Bscl}^{+/+}$males (Figure 1e). There was $15.8 \%$ reduction of absolute epididymis weight in $\mathrm{Bscl}^{-1-}$ males (Supplementary Figure S1B) but comparable relative epididymis weight with $\mathrm{Bscl}^{+/+}$males (Supplementary Figure S1C). Interestingly, significantly increased absolute and relative weights of seminal vesicles and attached coagulating glands were observed in $\mathrm{Bscl}^{-/}$males (Supplementary Figures S1D and E).

Sperm motility could contribute to male infertility and was analyzed in another set of males. The average sperm count in $\mathrm{Bscl}^{-1-}$ group was $\sim 3.3 \%$ of the control group (Supplementary Figure S1F). The average percentage of motile sperm in the same sperm preparations was $\sim 0.4 \%$ from $\mathrm{Bscl}^{-1-}$ males and $\sim 10.8 \%$ from control males (Figure 1f). Sperm motility is essential for sperm transport in female reproductive tract. ${ }^{18}$ The efficiency of sperm transport was expressed as the percentage of the uterine sperm count over the cauda epididymis sperm count of the mated male, which was $\sim 7.5 \%$ and $\sim 0.5 \%$ in $\mathrm{Bscl}^{+/+}$and $\mathrm{Bscl}^{-1-}$ males, respectively (Figure 1g, Supplementary Figures S1G and H). These data demonstrated reduced sperm count and defective sperm motility in $\mathrm{Bscl}^{-1-}$ males.

Histology showing defective spermatids and spermatozoa in $\mathbf{B s c l 2}^{-1-}$ males. Testis histology showed that the seminiferous epithelial thickness of the majority seminiferous tubules in $\mathrm{Bscl}^{-1-}$ testes from postnatal day 15 (PND15) to adult was comparable to their age-matched $\mathrm{Bscl}^{+/+}$control (Figures 2a-f). Spermatogonia and spermatocytes appeared comparable between $\mathrm{Bscl}^{-1-}$ and $\mathrm{Bscl}^{+/+}$seminiferous tubules. However, the spermatids, especially late-stage spermatids in the $\mathrm{Bscl} 2^{-1}$ seminiferous tubules appeared remarkably reduced (Figures $2 e$ and $f$ ). The elongated $\mathrm{Bscl}^{-1}$ - spermatids were often disorganized and were present throughout the seminiferous epithelium (Figures $2 \mathrm{~g}-\mathrm{j}$ ). The disorganized spermatids prevented accurate staging of spermatogenesis in the $B s c / 2^{-1-}$ testes, except for stages IX to $\mathrm{XI}$, which lack round spermatids. There was no difference in the average number of cross-sectioned seminiferous tubules per field $(\times 20)$ (Supplementary Figure S1I) or the average number of stages $I X$ to $X I$ seminiferous tubules (Supplementary Figure S1J) between $\mathrm{Bscl}^{+/+}$and $\mathrm{Bscl}^{-1-}$ testes. The average number of round spermatids per seminiferous tubule was significantly reduced in $\mathrm{Bscl}^{-1-}$ testes (Figure 2k). The cauda epididymis sperm density from $\mathrm{Bscl}^{-1-}$ males was dramatically decreased (Figures $2 \mathrm{l}$ and $\mathrm{m}$ ) and there were many round apoptotic cell bodies in $\mathrm{Bscl}^{-1}$

Figure 2 Histology of testis, cauda epididymis, and rete testis. $+/+, B s c / 2^{+++}$; $-/-, \mathrm{Bscl}^{-1-}$. Testes from three to six mice at each time point per genotype were analyzed. Representative images were shown. (a) PND15 Bscl2/+t testis. (b) PND15 $\mathrm{Bscl}^{-1-}$ testis. (c) PND35 Bscl2 ${ }^{+/+}$testis. (d) PND35 $\mathrm{Bscl}^{-1-}$ testis. Data in e-m were from 3- to 6-month-old (3-6 M) males. (e) Bscl2 ${ }^{+/+}$testis. (f) Bscl2 ${ }^{-1-}$ testis. (g-j) Enlarged views of $B s c l 2^{+/+}$(g and i) and $B s c / 2^{-1-}(\mathbf{h}$ and $\mathbf{j})$ seminiferous epithelia to show disorientated distribution of spermatids in the $\mathrm{Bscl}^{-}$- seminiferous epithelia. (k) Number of round spermatids per seminiferous tubule. $N=5-6$; error bar, S.D.; ${ }^{*} P<0.05$. (I) $B s c 2^{+/+}$cauda epididymis. (m) Bscl2 ${ }^{-1-}$ cauda epididymis. (o) Bscl2 ${ }^{+/+}$rete testis. (p) Bscl2 ${ }^{-1-}$ rete testis. $\mathbf{0}$ and $\mathbf{p}$, arrows indicating germ cells. Scale bar, $50 \mu \mathrm{m}$ cauda epididymis (Figure $2 \mathrm{~m}$ ) but not $\mathrm{Bscl}^{+/+}$cauda epididymis (Figure 2l). Rete testis histology showed scattered germ cells that were similar as those in the cauda epididymis (Figures 20 and $\mathrm{p}$ ).
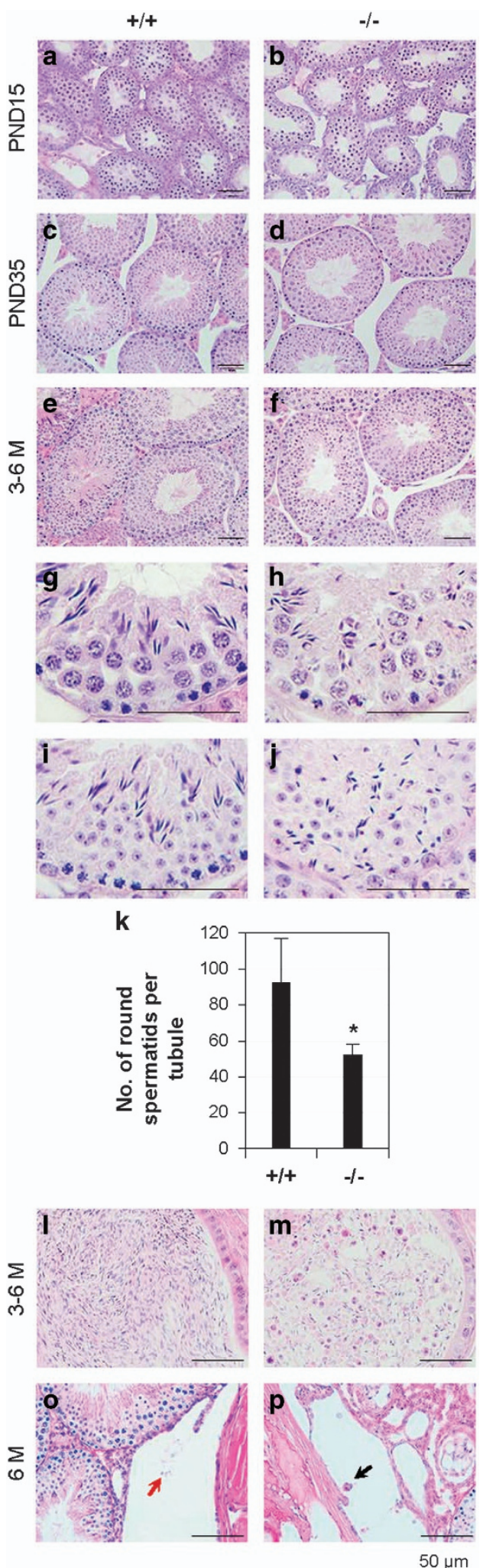
Spatiotemporal expression of $\mathrm{Bscl} 2 /$ seipin in $\mathrm{Bscl}^{+/+}$ testis. Quantitative RT-PCR indicated $>10$-fold increase of Bscl2 mRNA level in the 3-month-old $\mathrm{Bscl}^{+/+}$testes compared with PND15 $\mathrm{Bscl}^{+/+}$testis (Supplementary Figure S2A). In-situ hybridization revealed that Bscl2 mRNA was barely detectable in most areas, except faint staining in some seminiferous tubules in the PND15 testis (Figure 3a) and gradually increased in PND20 (Figure 3b) and PND25 testes (Figure 3c). In PND28 testis, Bscl2 mRNA was detected in all seminiferous tubules, although the levels of expression varied among different seminiferous tubules (Figure 3d). This Bscl2 mRNA expression pattern remained throughout the 7-month-old testis, the oldest time point examined (Figure 3e). Within the seminiferous tubules, the highest expression levels were detected in the spermatocytes (Figure $3 \mathrm{~g}$ ). Based on a study about spermatogenic cells in prepubertal mouse testis, ${ }^{19}$ Bscl2 mRNA was most likely expressed in both pachytene spermatocytes and secondary spermatocytes. Bscl2 mRNA did not seem to be expressed in spermatogonia and Sertoli cells (Figure $3 \mathrm{~g}$ ). The signals in the interstitial spaces were insignificant (Figures $3 d$, e, and g). The negative control using a sense probe did not detect any positive signal (Figures $3 f$ and h). Interestingly, Bscl2 mRNA was highly and specifically detected in the epithelium of coagulating gland and seminal vesicle (Supplementary Figures S2B-F).
Immunohistochemistry analysis showed an age-dependent increase of seipin expression in the seminiferous tubules from PND15 to 3 months old (Figures 3i-n). On PND25, seipin started to be detected in the round spermatids and remarkably increased in the spermatids afterwards. IgGnegative control or $\mathrm{Bscl}^{-/-}$testis did not show specific staining (Figures 30 and p). Both histology (Figures $2 a-f$ ) and seipin expression suggested potential role of seipin in spermatid development or spermiogenesis.

Increased $\mathrm{ISEL}^{+}$staining in Bscl2 ${ }^{-1-}$ testis. Immunohistochemical analysis of cleaved caspase- 3 did not show an obvious difference between $\mathrm{Bscl}^{+/+}$and $\mathrm{Bscl}^{-/-}$testes. A few cleaved caspase-3-positive germ cells were detected in both genotypes (Supplementary Figure S3). In situ endlabeling plus (ISEL ${ }^{+}$) detects DNA breaks. ${ }^{20,21}$ Both $\mathrm{BsCl}^{+/+}$ and $\mathrm{Bscl}^{-1-}$ males had widespread $\mathrm{ISEL}^{+}$labeling (Supplementary Figure S4). However, $\mathrm{Bscl}^{-1-}$ testis sections (Supplementary Figure S4D) showed consistently more $\mathrm{ISEL}^{+}$labeling than $\mathrm{Bscl}^{+/+}$testis sections (Supplementary Figure S4A). Quantification using ImageJ indicated a 10-fold increase of $\mathrm{ISEL}^{+}$labeling intensity in $\mathrm{Bscl}^{-/}$testis sections (Figure 4a), for which clusters of $\mathrm{ISEL}^{+}$labeled cells were a main contributor (Figures $4 b$ and $d$, and Supplementary Figure S4). Individual $\mathrm{ISEL}^{+}$labeled cells not in the clusters were also detected in both $\mathrm{Bscl}^{+/+}$and
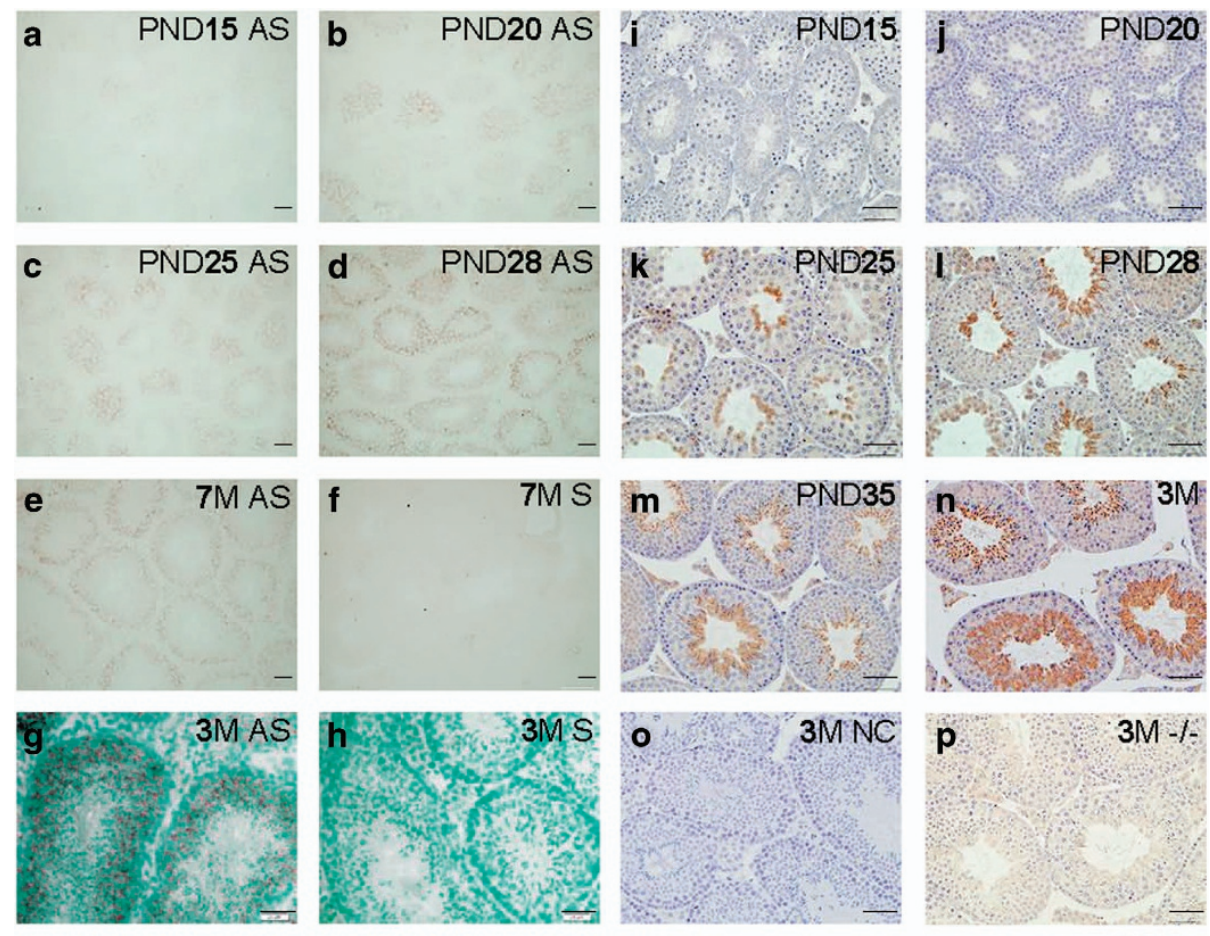

$50 \mu \mathrm{m}$

Figure 3 Spatiotemporal localization of Bscl2 mRNA by in situ hybridization (a-h) and seipin protein by immunohistochemistry (i-p) in the testis. All sections were from $B s c / 2^{+/+}$testes except $\mathbf{p}$, which was from a Bscl2 ${ }^{-1-}$ testis. Testes from at least three mice at each time point were analyzed. Representative images were shown. (a) PND15, antisense (AS) probe. (b) PND20, antisense probe. (c) PND25, antisense probe. (d) PND28, antisense probe. (e) 7-Month-old (7M), antisense probe. (f) 7M, sense probe, negative control. (g) 3M, antisense probe. (h) 3M, sense probe. ( $\mathbf{g}$ and $\mathbf{h}$ ) Counterstained with methyl green. (i-p) All sections were incubated with primary anti-seipin antibody, except o, which was incubated with normal rabbit lgG. (i) PND15. (j) PND20. (k) PND25. (I) PND28. (m) PND35. (n) 3M. (o) 3M, negative control (NC). (p) 3M, Bscl2 ${ }^{-1-}$ (- / - ), a second negative control. Scale bar, $50 \mu \mathrm{m}$ 
a
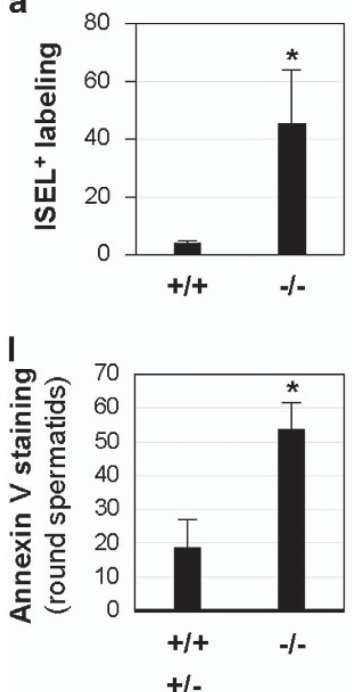

$+/+$
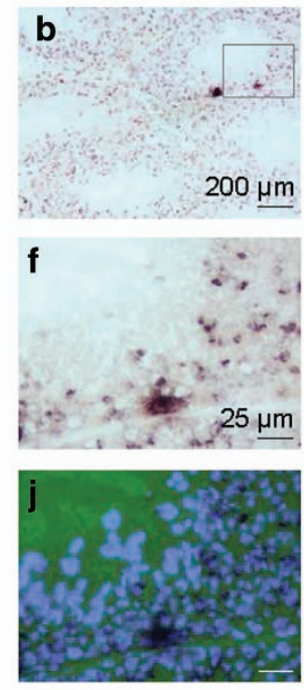
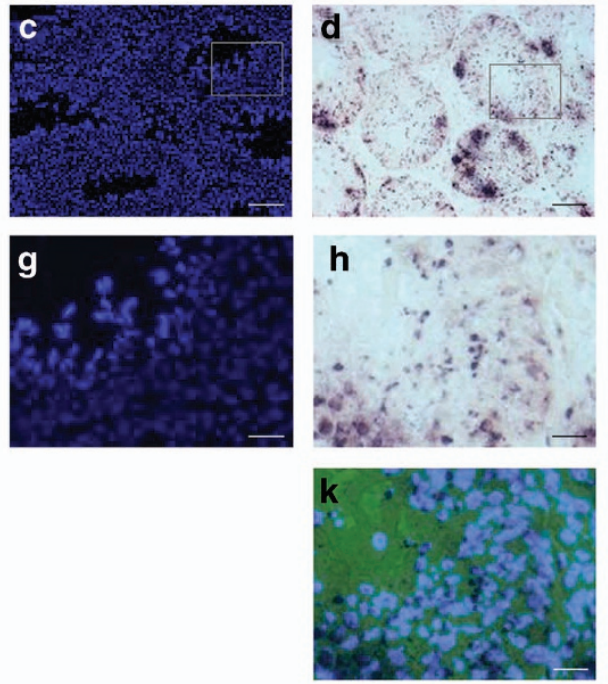

$-/-$

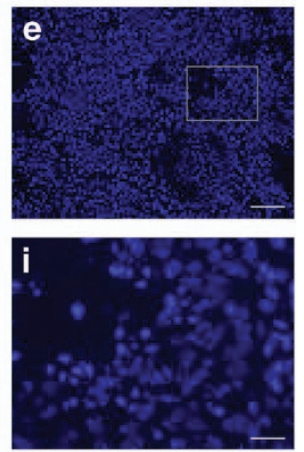

Figure 4 ISEL ${ }^{+}$and annexin V staining of male germ cells. (a-k) ISEL ; 3- to 4-month-old $B s c l 2^{+/+}(+/+)$and $B s c l 2^{-/-}(-/-)$males; $N=5$. (a) Quantification of ISEL ${ }^{+}$ labeling using ImageJ as described in Materials and Methods. The original images used for quantification were in Supplementary Figure S4. (b) A representative ISEL ${ }^{+}$testis section from a Bscl2 $2^{+/+}$male. (c) DAPI counterstaining of the section in $\mathbf{b}$. (d) A representative ISEL testis section from a Bscl2 ${ }^{\prime-}$ male. (e) DAPI counterstaining of the section in $\mathbf{d}$. Scale bars in $\mathbf{b}-\mathbf{e}, 200 \mu \mathrm{m}$. (f-i) Enlarged images of the rectangle areas in $\mathbf{b}-\mathbf{e}$, respectively. (j) Merged image of $\mathbf{f}$ and $\mathbf{g}$. (k) Merged image of $\mathbf{h}$ and $\mathbf{i}$. Scale bars in $\mathbf{f}-\mathbf{k}$, $25 \mu \mathrm{m}$. Dark dots and clusters in $\mathbf{b}, \mathbf{d}, \mathbf{f}, \mathbf{h}, \mathbf{j}$, and $\mathbf{k}$ were ISEL ${ }^{+}$labeling. (I) Percentage of annexin V-positive round spermatids in 5-month-old control $\left(B s c l{ }^{+/+}(+/+)\right.$and $B s c l{ }^{+/-}$ $(+/-), N=3)$ and $B s c l 2^{-1-}(-I-)(N=4)$ males. (a and I) ${ }^{*} P<0.05$; error bar, S.D.

$\mathrm{Bscl}^{-1-}$ testis sections. These cells were located in the $\mathrm{BsCl}^{+/+}$seminiferous epithelium but rarely in the area close to the lumen where spermatids and sperm reside (Figures 4b, c, f, g, and j, and Supplementary Figures S4A-C). However, $\mathrm{ISEL}^{+}$labeled cells were detected throughout $\mathrm{Bscl}^{-1-}$ seminiferous epithelium, including the area where spermatids and sperm resided (Figures $4 d, e, h$, i, and k, and Supplementary Figure S4F), indicating increased DNA breaks and apoptosis of the $B s c / 2^{-1-}$ spermatids and sperm.

Annexin $\mathrm{V}$ staining detects cells in the intermediate stages of apoptosis. To support the association of increased DNA breaks in $\mathrm{Bscl}^{-1-}$ late germ cells detected by $\mathrm{ISEL}^{+}$with apoptosis, round spermatids were examined for annexin $\mathrm{V}$ staining in germ cell spreads. Results indicated significantly increased percentage of annexin $\mathrm{V}$-positive $\mathrm{Bscl}^{-/-}$round spermatids (Figure 4I).

Normal meiotic chromosome pairing and homologous chromosome synapsis in $\mathrm{Bscl}^{-/-}$spermatocytes. To determine the causes of DNA breaks in the late $\mathrm{BsCl}^{-1}$ germ cells, germ cell spreads from seminiferous tubules were analyzed. As Bscl2 mRNA was mainly detected in the spermatocytes (Figure $3 \mathrm{~g}$ ), spermatocytes were examined. Pairing and subsequent synapsis of homologous chromosomes are essential developmental events necessary for proper meiotic recombination and chromosome segregation during metaphase I and II. ${ }^{22}$ The structural chromosome proteins synaptonemal complex proteins 3 and 1 (SYCP3 and SYCP1) are key components of axial (SYCP3) and lateral (SYCP1) elements of the synaptonemal complex ${ }^{23,24}$ and were used as bona fide markers for prophase I of meiosis. SYCP3 was first detectable in leptotene-stage spermatocytes of both $\mathrm{Bscl}^{+/+}$and $\mathrm{Bscl}^{-/-}$preparations and progressively labeled the axial extension of the condensing chromosomes during zygotene and pachytene stages without indication for chromosome pairing errors (data not shown). This observation was also confirmed in synapsis of homologous chromosomes as indicated by co-localization of SYCP3 and SYCP1 in all autosomes at the pachytene stage of meiosis, irrespective of the genotypes (Supplementary Figure S5). In addition, the $X$ and $Y$ chromosomes were partially synapsed at the pseudoautosomal region in both $\mathrm{Bscl}^{+/+}$and $\mathrm{Bscl}^{-/-}$pachytene spreads (Supplementary Figure S5), indicating that $\mathrm{Bscl}^{-1-}$ spermatocytes did not present obvious synaptic errors during prophase I.

Chromocenter fragmentation in $\mathrm{Bscl}^{-1-}$ round spermatids. As seipin is highly expressed in the postmeiotic spermatids (Figure 3), we analyzed global chromatin structure during spermiogenesis. SYCP3 is a marker of meiotic cells and is normally absent in the spermatids (Figures 5a-c). ${ }^{25,26}$ However, there was an increased percentage of $\mathrm{Bscl}^{-1}$ round spermatids with retained SYCP3 expression (Figures $5 \mathrm{~d}-\mathrm{g}$ ). Surface spreading of germ cell nuclei allows fine structural analyses of the subnuclear localization and distribution of chromatin domains. The chromocenter is a cluster of centromeres and pericentromeric heterochromatin. ${ }^{27}$ As a hallmark of spermiogenesis, centromeric heterochromatin domains of the autosomes coalesce to one or two central chromocenters with adjacent sex chromatin. ${ }^{28}$ In surface spreads obtained from $\mathrm{Bscl}^{-1-}$ males, a significant proportion of round spermatids $(31.0 \%$, $P=0.032)$ exhibited fragmentation of the chromocenter into three or more heterochromatic foci as demonstrated by labeling with a bona fide marker for centromeric heterochromatin, H3K9me3 (histone H3 trimethylated at lysine 9), ${ }^{29}$ 
whereas this phenotype was detectable in only $7.1 \%$ of $\mathrm{Bscl}^{+/+}$control (Figures $5 \mathrm{~h}-\mathrm{n}$ ). These findings indicated abnormalities in the regulation of chromocenter formation in
$\mathrm{Bscl}^{-1-}$ males that may lead to defects in chromatin condensation and formation of proper spermatozoa and mature sperm.
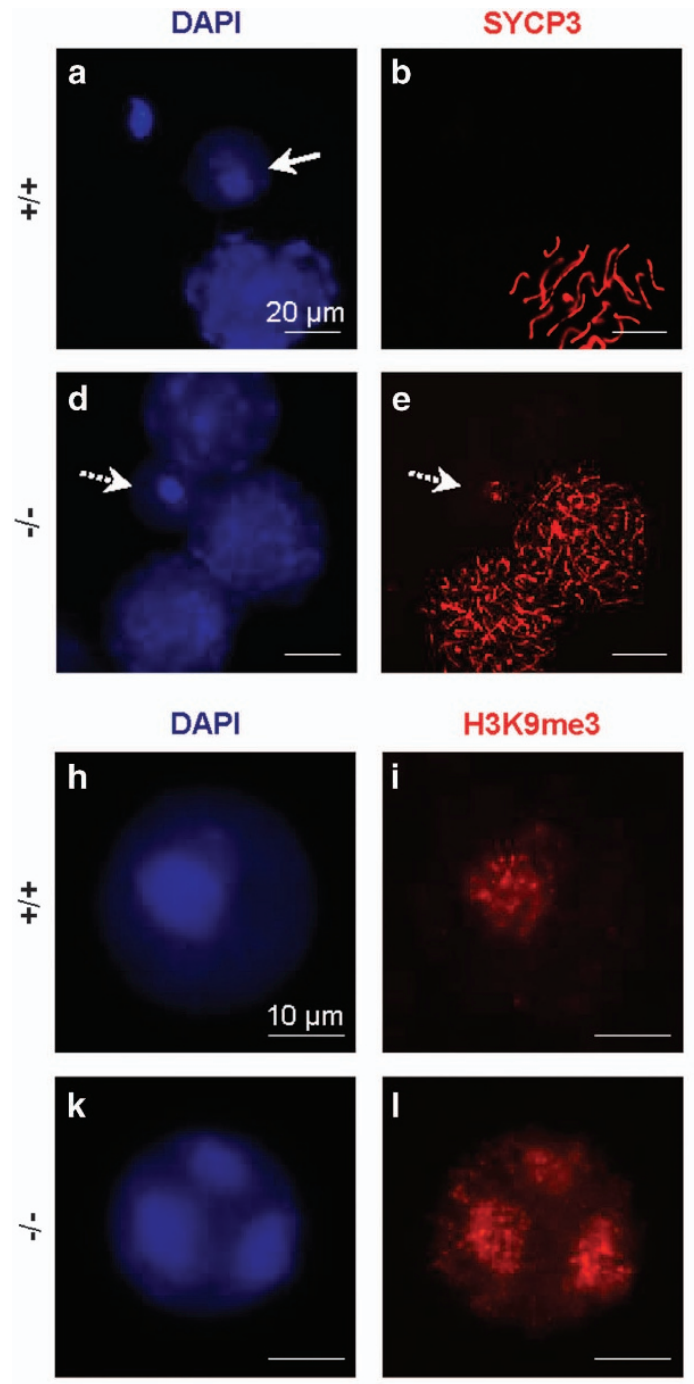

\section{H3K9me3}
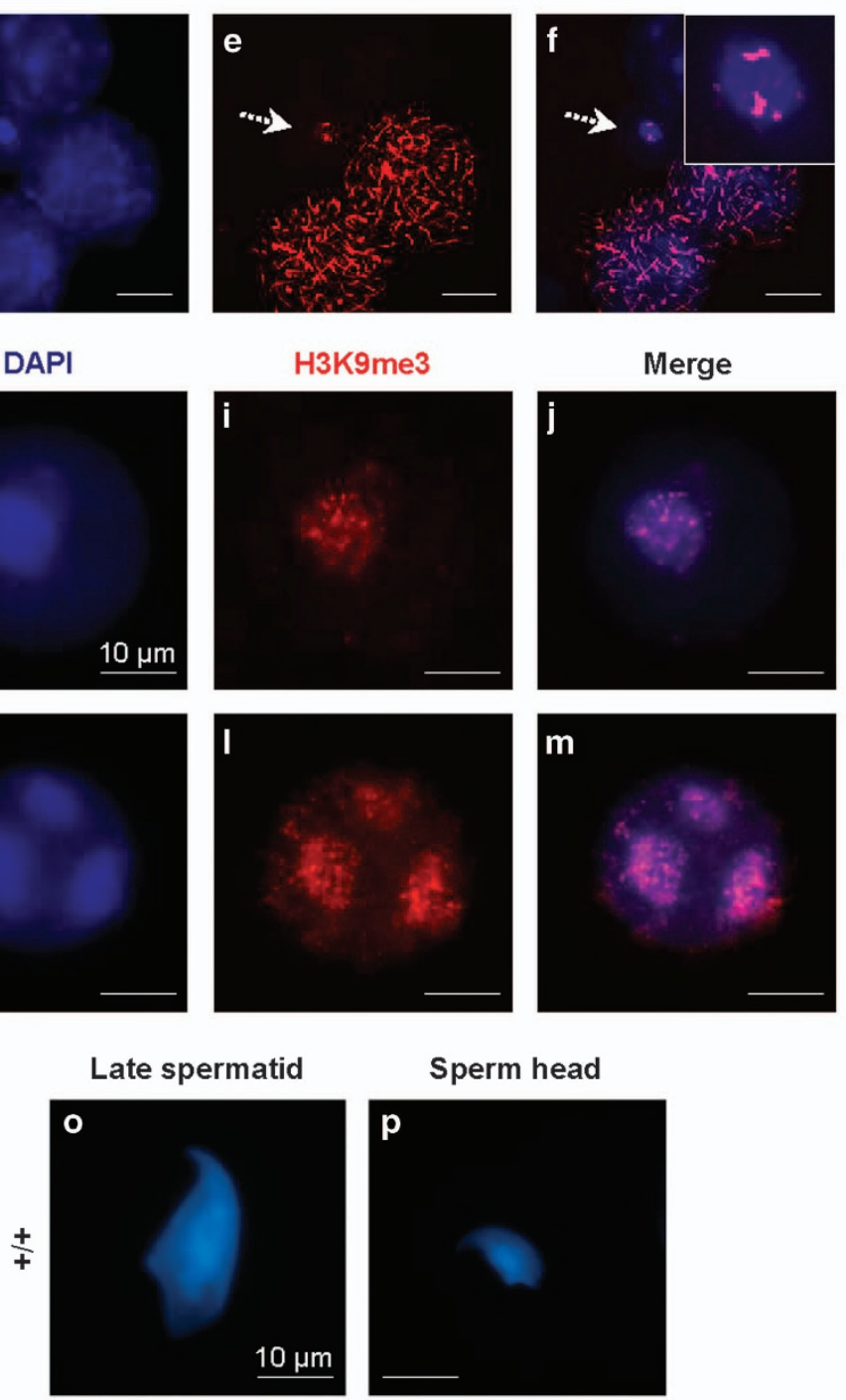

\section{Sperm head}
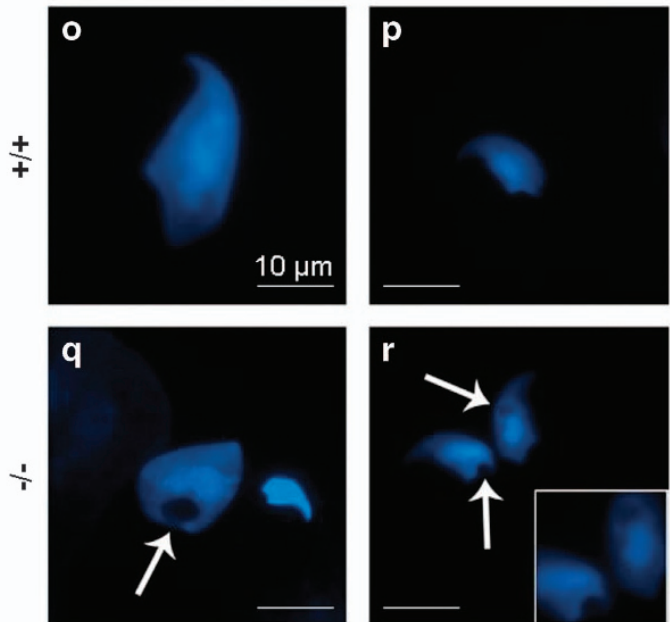

m

Merge

Merge

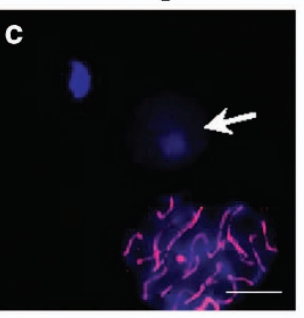

g
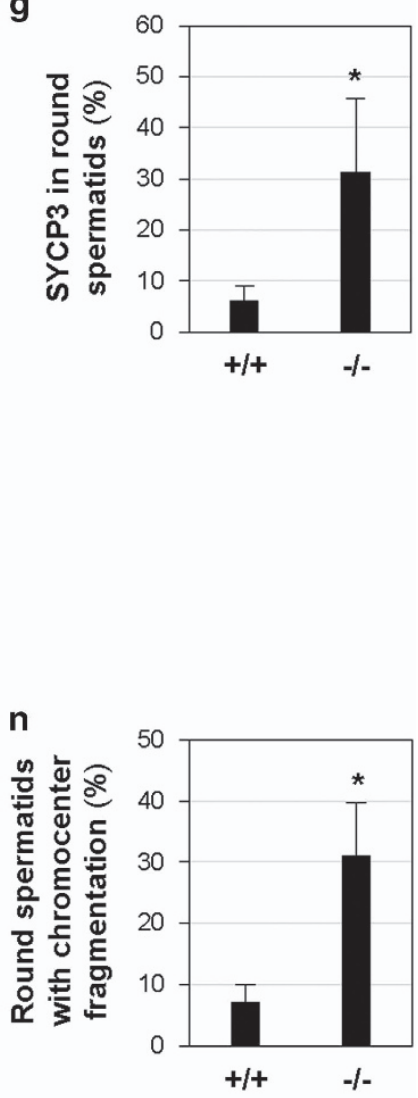

s

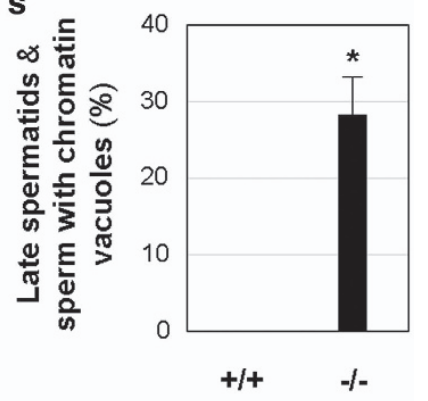



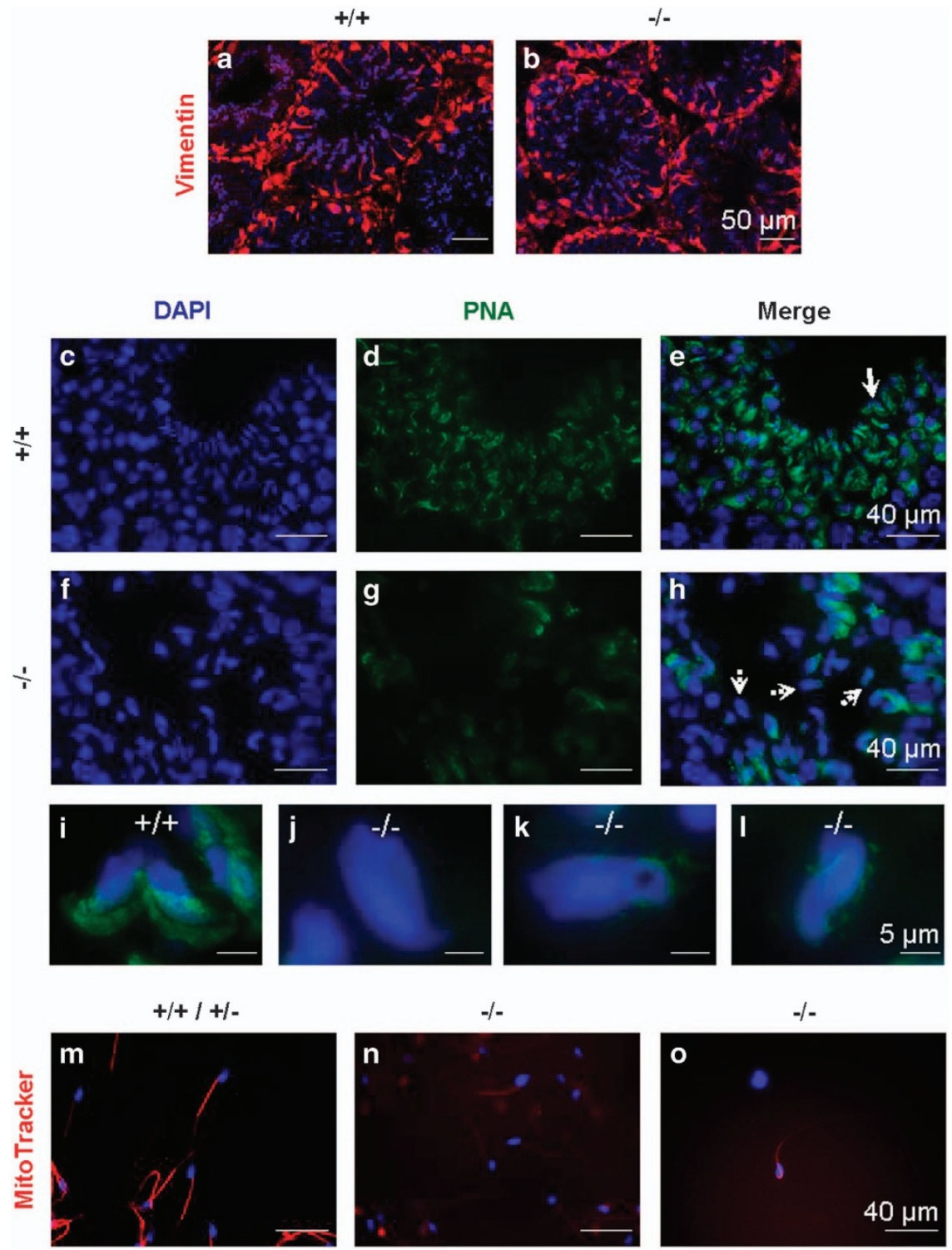

Figure 6 Detection of Sertoli cells, acrosomes, and active mitochondria. +/+, Bscl2 ${ }^{+/+} ;-/-, B s c 2^{-1-}$. Sertoli cells were labeled by vimentin (red) immunofluorescence. Acrosomes were labeled with Alexa Fluor 488-conjugated PNA (green). Testes from 3- to 4-month-old mice $(N=3-4)$ were used. (a) $B s c l 2^{+/+}$testis vimentin labeling. (b) $B s c l 2^{-1-}$ testis vimentin labeling. (c) DAPI staining of $B s c / 2^{++}$seminiferous epithelium. (d) PNA staining of the section in $\mathbf{c}$. (e) Merged image of $\mathbf{c}$ and $\mathbf{d}$. (f) DAPI staining of Bscl2 ${ }^{-/-}$

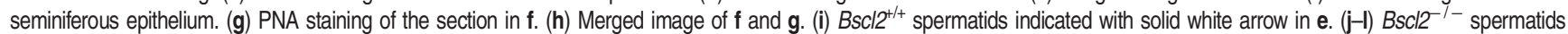
indicated with dashed white arrows in $\mathbf{h}$. The spermatid in $\mathbf{k}$ had chromatin vacuole. Scale bar, $50 \mu \mathrm{m}$ in $\mathbf{a}$ and $\mathbf{b}, 40 \mu \mathrm{m}$ in $\mathbf{c}-\mathbf{h}$, and $5 \mu \mathrm{m}$ in $\mathbf{i}-\mathbf{I}$. ( $\mathbf{m}-\mathbf{0})$ Red, MitoTracker staining of mitochondria at midpiece of sperm from 5-month-old cauda epididymis; blue, DAPI staining sperm head. (m) Representative control $\left(\mathrm{Bscl}^{+/+} \& \mathrm{Bscl}^{2^{+/}}\right)$sperm with strong staining on midpiece. (n) Representative $B s c / 2^{-1-}$ sperm with faint staining. (o) A Bscl2 ${ }^{-1}$ sperm with strongest red stain in the group. Note, increased exposure in $\mathbf{n}$ and $\mathbf{o}$ to show Bscl2 $^{-1-}$ sperm midpiece

Figure 5 Analyses of round spermatids, late spermatids, and sperm in 4-month-old $B s c / 2^{+/+}(+/+)$and $B s c / 2^{-1-}(-/-)$ germ cell spreads. (a-c) A representative image from $\mathrm{Bscl}^{+/+}$spreads; white arrows indicating a round spermatid. (a) DAPI. (b) SYCP3 staining the chromosomes in a pachytene spermatocyte in $\mathbf{a}$. (c) Merged image of a and $\mathbf{b}$. (d-f) A representative image from Bscl2 ${ }^{-1-}$ spreads; white arrows with a broken line indicating a round spermatid. (d) DAPI. (e) SYCP3 staining the chromosomes in the zygotene spermatocytes and the round spermatid in $\mathbf{d}$. (f) Merged image of $\mathbf{d}$ and $\mathbf{e}$. Insert, enlarged view of the round spermatid with retained SYCP3 staining. (g) Percentage of round spermatids with retained SYCP3 staining. (h) Blue DAPI staining of a representative Bscl2 ${ }^{\text {t+ }}$ round spermatid. (i) Red H3K9me3 staining of the round spermatid in $\mathbf{h}$. (j) Merged image of $\mathbf{h}$ and $\mathbf{i}$. (k) Blue DAPI staining of a representative Bscl2 ${ }^{\prime-}$ round spermatid. (I) Red H3K9me3 staining of the round spermatid in $\mathbf{k}$ showing chromocenter fragmentation. ( $\mathbf{m}$ ) Merged image of $\mathbf{k}$ and $\mathbf{I}$. (n) Percentage of round spermatids with chromocenter fragmentation. (o-r) Representative DAPI staining of late spermatids and sperm. (o) A Bscl2 ${ }^{+/+}$late spermatid. (p) A Bscl2 $2^{++}$sperm head. (q) A Bscl2 ${ }^{-1-}$ late spermatid and sperm head. (r) Two Bscl2 ${ }^{-1-}$ sperm heads. Insert, enlarged view of the chromatin vacuoles. Arrowheads in $\mathbf{q}$ and $\mathbf{r}$, chromatin vacuoles. Scale bar, $10 \mu \mathrm{m}$. (s) Percentage of late spermatids and sperm with chromatin vacuoles. (g, $\mathbf{n}$, and $\mathbf{s})$ At least 100 randomly selected round spermatids from each sample were examined; $N=3$; error bars, S.D.; ${ }^{*} P<0.05$ 
High incidence of chromatin vacuoles in $\mathrm{Bscl}^{-1-}$ late spermatids and mature sperm. To address whether loss of seipin led to abnormal sperm chromatin condensation, morphological analyses were conducted using highresolution microscopy of surface-spread germ cells. Bscl2-/late (elongating) spermatids and mature spermatozoa had a high incidence $(28.2 \%, P<0.001)$ of chromatin vacuoles, which were not restricted to any particular nuclear domain, whereas such abnormalities were never observed in $\mathrm{Bscl}^{+/+}$ germ cell preparations (Figures 50-s).

Chromocenter fragmentation in round spermatids and chromatin vacuoles in late spermatids and mature sperms indicated potential problems in chromatin condensation, a process involving protamines 1 and 2 (PRM1/2) in mice. ${ }^{27,30,31}$ Although the levels of Prm1 mRNA and Prm2 mRNA, which are expressed in round spermatids, ${ }^{32,33}$ were significantly reduced in 3-month-old $\mathrm{Bscl}^{-1-}$ testes compared with $\mathrm{Bscl}^{+/+}$testes, the levels of PRM1 and PRM2 proteins, which are expressed in late spermatids and sperm, were comparable in the nuclei of individual $\mathrm{Bscl}^{+/+}$and $\mathrm{Bscl}^{-/-}$late spermatids and sperm (Supplementary Figure S6). Downregulation of Prm1 and Prm2 mRNAs in the $\mathrm{Bscl}^{-1-}$ testis most likely resulted from the reduced number of round spermatids (Figure 2k and Supplementary Figures S6A and B). These data demonstrated that protamines most likely did not contribute to the chromatin defects in $\mathrm{Bscl}^{-1-}$ late spermatids and sperm.

Defective acrosome formation in $\mathrm{Bscl}^{-1-}$ late spermatids. Besides chromocenter fragmentation in round spermatids and chromatin vacuoles in late spermatids and mature sperms, $\mathrm{Bscl}^{-1-}$ late spermatids were disorganized and were present throughout seminiferous epithelium (Figures $2 \mathrm{~h}$ and j, and Supplementary Figures S6I and R). Late spermatids are associated with Sertoli cells, which could be stained with vimentin. There was comparable vimentin staining between $\mathrm{Bscl}^{+/+}$and $\mathrm{Bscl}^{-/-}$testes (Figures $6 \mathrm{a}$ and $b$ ), indicating no obvious structural abnormality of the Sertoli cells that support sperm cell development before the spermatids are released to the lumen.

It was previously suggested that an acrosome may be related to the alignment of the spermatid head with the ectoplasmic specialization to influence the orientation and positioning of the late spermatids within the seminiferous epithelium. $^{34}$ Peanut agglutinin (PNA) staining revealed crescent-shaped acrosomes in $\mathrm{Bscl}^{+/+}$late spermatids (Figures 6c-e and i). However, Bscl2 ${ }^{\prime-}$ spermatids had abnormal acrosomes (Figures $6 f-h$ and $j-l$ ), such as no defined acrosome (Figure 6j), irregular-shaped acrosome (Figure 6k), and fragmented acrosome (Figure 6l). These data demonstrated that seipin deficiency also affected acrosome formation in late spermatids.

Defective mitochondrion function in $\mathrm{Bscl}^{-I-}$ sperm. Besides low sperm count (Figure 1e), the $\mathrm{Bscl}^{-1-}$ sperm also had low sperm motility (Figure 1f). It has been demonstrated that there is direct and positive correlation between mitochondrial enzymatic activities and sperm motility. ${ }^{35}$ MitoTracker, which stains active mitochondria, was used to determine mitochondrial activity of sperm freshly isolated from the cauda epididymis. The majority of control sperm were motile and had strong staining at the midpiece (Figure $6 \mathrm{~m}$ ). However, the majority of $\mathrm{Bscl}^{-/-}$sperm were immotile and the MitoTracker staining was so weak that increased exposure time was required to visualize the flagellum (Figure 6n); even the strongest stained $\mathrm{Bscl}^{-1-}$ sperm required increased exposure time (Figure 6o).

\section{Discussion}

This study systemically analyzed the spatiotemporal expression of Bscl2 mRNA and seipin protein in the mouse testis. Although both mRNA and protein levels gradually increased in the postnatal testes, with detectable levels by both in situ hybridization and immunohistochemistry after PND20, the mRNA levels seemed to reach a plateau $\sim$ PND28, while the protein levels were still increasing $\sim$ PND35. This was due to the main protein localization of seipin in spermatids. Round spermatids start to appear after PND18 and elongating spermatids start to appear $\sim$ PND35 and continue to develop till adulthood. ${ }^{19,36}$ The temporal expression of seipin protein correlated with the onset of spermiogenesis and suggested its potential function in spermiogenesis. Indeed, in seipindeficient testis, there was a reduction of round spermatids; escaping spermatids often lacked normal maturation features and showed signs of DNA damages; only a limited number of spermatids would go into the elongation phase, yet they would have aberrations such as chromatin vacuoles and abnormal acrosome formation; and the minimal number of sperm produced had diminished mitochondrial activity and motility.

Interestingly, Bscl2 mRNA and seipin were not co-localized in the same male germ cells, with the mRNA mainly in the spermatocytes and the protein mainly in the spermatids, indicating translational repression in the spermatocytes. Translational repression in the male germ cells has also been reported for other genes in the testis. For example, mRNAs for transition proteins and protamines are synthesized in round spermatids but translated in elongated spermatids. ${ }^{32,33}$

There were increased percentages of round spermatids with retained SYCP3 expression or chromocenter fragmentation in the $\mathrm{Bscl}^{-/-}$germ cell spreads. Although it is unknown about the significance of retained SYCP3 expression in the round spermatids, chromocenter fragmentation could lead to defects in chromatin condensation and the formation of proper spermatozoa and mature sperm. Chromocenter fragmentation has been reported in mice lacking the first bromodomain of testis-specific double bromodomain protein $\mathrm{Brdt}^{37}$ and mice deficient of TBP-like factor, ${ }^{38}$ both of which have impaired male fertility. ${ }^{37-39}$ Interestingly, the former was not associated with spermatid apoptosis ${ }^{37}$ but the later was associated with increased spermatid apoptosis. ${ }^{39}$

There were increased $\mathrm{ISEL}^{+}$labeled cell clusters in $\mathrm{Bscl}^{-/-}$ seminiferous epithelium as well as increased $\mathrm{ISEL}^{+}$labeled individual spermatids at the center or close to the lumen of $\mathrm{Bscl}^{-1}$ - seminiferous tubules. Male germ cell apoptosis is a normal process during spermatogenesis. ${ }^{14}$ It is most likely that chromocenter fragmentation contributed to the increased spermatid apoptosis in Bscl2 $/$ - testis. However, the causes for increased $\mathrm{ISEL}^{+}$labeled cell clusters in the $\mathrm{Bscl}^{-1-}$ seminiferous epithelium are unknown. Such clusters were also 
seen in the $\mathrm{Bscl}^{+/+}$seminiferous epithelium but at a much less frequency. As spermatids are connected by cytoplasmic bridges and $\mathrm{Bscl}^{-1-}$ spermatids were often observed in abnormal locations near the periphery of seminiferous tubule, it is possible that the increased ISEL ${ }^{+}$labeled cell clusters near the base of seminiferous epithelium was due to increased $\mathrm{Bscl}^{-1-}$ spermatid apoptosis. In addition, as germ cells at different stages are supported by the same Sertoli cells, it is unknown whether the defects in the spermatids could affect earlier germ cells that share the same Sertoli cells. The increased germ cell death in the $\mathrm{Bscl}^{-1-}$ testis was obviously unassociated with caspase- 3 pathway. This scenario had been reported in RARalpha ${ }^{-1-}$ testes as well, ${ }^{40}$ which also had disorganized late spermatids and increased spermatid apoptosis.

Chromatin vacuoles were only observed in late spermatids and spermatozoa from the $\mathrm{Bscl} 2^{-1-}$ testis. As the localizations of the chromatin vacuoles could be found in different areas, it is possible that these vacuoles are formed by defects in largescale chromatin condensation during spermatid elongation and thus had much less density on DAPI (4',6-diamino-2phenylindole) staining. It is possible that defects in chromatin condensation might be associated with chromocenter fragmentation in round spermatids. One study revealed that the small vacuoles in human sperm were abnormal nuclear concavities associated with noncondensed chromatin. ${ }^{41}$ Chromatin vacuoles are also observed in sperm deficient of chromodomain helicase DNA-binding protein $5 .^{27}$

One defect in the $\mathrm{Bscl}^{-1-}$ testis was the disorganized late spermatids. Although the role of acrosome in spermatid orientation has not been established, it was suggested decades ago that an acrosome may have a role in aligning the spermatid head with the ectoplasmic specialization to influence the orientation and positioning of the late spermatids. $^{34}$ The Bscl $^{-/-}$spermatids had various defects in their acrosomes and were often disorganized. Seipin was shown to be localized on the ER membrane. ${ }^{4,5}$ ER is closely associated with the Golgi apparatus where the acrosome is derived from. It is possible that seipin is directly involved in acrosome formation in late spermatids.

A recent study on $\mathrm{Bscl}^{-1-}$ testes from a different line of global seipin knockout mice and germ cell conditional knockout mice demonstrated that the defective sperm production was due to local deficiency of seipin in the germ cells. ${ }^{10}$ The percentages of motile sperm were much lower in our study, which was due to different sample preparations. Increased phosphatidic acid (PA) level was observed in the $\mathrm{Bscl}^{-1-}$ testis. ${ }^{10}$ Phospholipases $A \mathrm{PLA}_{1}$ and $\mathrm{PLA}_{2}$ are involved in PA metabolism. PA-preferring $\mathrm{PLA}_{1}\left(\mathrm{PA}-\mathrm{PLA} \mathrm{A}_{1}\right)$ is highly

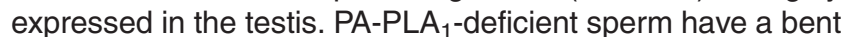
flagellum and severely impaired sperm motility. ${ }^{42}$ Sperm tail defects were also observed in the $\mathrm{Bscl}^{-1-}$ sperm, ${ }^{10}$ which might be related to the function of PA-PLA $A_{1}$ in flagellum and sperm motility. ${ }^{42}$ In addition, lack of active mitochondria in the $\mathrm{Bscl}^{-1-}$ sperm midpiece could be a main reason for defective sperm motility.

In addition to its critical role in adipogenesis, ${ }^{11,12} \mathrm{Bscl} /$ seipin most likely has other uncharacterized roles. Its transcriptional upregulation in mES cells on exposure to genotoxins involving the ATR signaling pathway ${ }^{16,17}$ would suggest its potential role in maintaining DNA integrity on genotoxic insults. Although testicular-derived seipin was suggested to be essential for male fertility by modulating testicular phospholipid homeostasis, ${ }^{10}$ we assume that defective lipid homeostasis in $\mathrm{Bscl}^{-/-}$male germ cells could contribute to a defective flagellum with low mitochondrial activity and thus impaired sperm motility, whereas impaired DNA integrity and chromatin condensation could contribute to both reduced sperm count and impaired sperm motility, because DNA damage can induce apoptosis and is negatively related with sperm motility. ${ }^{43,44}$ Reduced sperm count, reduced sperm motility, and defective acrosome formation contribute to male infertility in the $\mathrm{Bscl}^{-1-}$ mice.

\section{Materials and Methods}

Animals. Bscl2-deficient mice $\left(\mathrm{Bscl}^{-1-}\right)$ in $\mathrm{C} 57 \mathrm{BL} / 6 \mathrm{~J}$ background were derived from a colony at Georgia Regents University, which was originally derived from a colony at Baylor College of Medicine, with backcrosses to C57BL/6 J background for five generations. ${ }^{8}$ They were genotyped as previously described, ${ }^{8}$ using mouse tail genomic DNA and PCR with wild-type allele-specific forward primer $5^{\prime}$-GGACGTGATCGGGTGAGTATGAGAA-3' and reverse primer $5^{\prime}$-GAGATA GGGTCTGGCTATGAA-3', and the neo-specific primer $5^{\prime}$-CTATCGCCTTCTTG ACGAGT-3'. All mice were maintained on PicoLab mouse diet 20 with soybean as a main protein source. They were housed in polypropylene cages with free access to food and water on a $12 \mathrm{~h}$ light/dark cycle $\left(0600-1800 \mathrm{~h}\right.$ ) at $23 \pm 1^{\circ} \mathrm{C}$ with $30-50 \%$ relative humidity at the College of Veterinary Medicine animal facility at the University of Georgia. The animals were killed by $\mathrm{CO}_{2}$ inhalation followed with cervical dislocation. All methods used in this study were approved by the University of Georgia Institutional Animal Care and Use Committee (IACUC) Committee and conform to National Institutes of Health guidelines and public law.

Male mating behavior and fertility tests. $\mathrm{Bscl}^{+/+}$males $(N=7)$ and $\mathrm{Bscl}^{-1-}$ males $(\mathrm{N}=10)$ at 2-3 months old were each housed with one 2-monthold virgin $\mathrm{Bscl}^{+/+}$female for 2 months. Each female was checked for the presence of a vaginal plug every morning, to determine mating activity during the previous night. Mating activity was evaluated with two parameters, plugging latency (the duration between cohabitation and the detection of the first plug) and plugging rate (the percentage of males in each group that ever successfully mated with females during the 2 months of cohabitation). Fertility was assessed using the litter size at birth and the number of litters per female. At the end of the 2-month-cohabitation, the males were separated from the mating females and the females were observed for 3 more weeks for pregnancies that occurred during the last period of mating study. The average ages of males were $\sim 20$ weeks old for both $\mathrm{Bscl}^{+/+}$ $(20.4 \pm 3.8$ weeks $)$ and $B s c l 2^{-1-}(20.0 \pm 2.3$ weeks $)$ males. Two $B s c / 2^{+/+}$males and three $B s c / 2^{-1-}$ males that finished mating and fertility tests before the rest males were killed for sperm counting only, the rest five $\mathrm{Bscl}^{+/+}$males $\left(20.6 \pm 4.4\right.$ weeks old) and seven Bscl2 ${ }^{-1-}$ males $(19.9 \pm 0.6$ weeks old $)$ were mated with one virgin female (2-3 months old) each for determining sperm count in the uterus before being killed for sperm counting. Positive mating was determined by the presence of a vaginal plug in the morning and the uterine horns from the positively mated females were flushed with $1 \times$ PBS for sperm counting from the uterus. Cauda epididymis sperm count was determined 1 week after mating and uterine sperm count was determined in the morning after mating. The efficiency of sperm transport was expressed as the percentage of the uterine sperm count over the cauda epididymis sperm count of the mated male.

Sperm count and sperm motility. All males were housed individually for 1 week before sperm counting. Each cauda epididymis was dissected, finely minced in $1 \mathrm{ml} 1 \times$ PBS in a $1.5-\mathrm{ml}$ microcentrifuge tube, and shaken at $37^{\circ} \mathrm{C} / 5 \% \mathrm{CO}_{2}$ for $30 \mathrm{~min}$. Sperm count was expressed as the total sperm number from both cauda epididymides. As sperm motility was not determined in the males from mating study, another set of males was used. Both $B s c 2^{+/+}$and $B s c l 2^{+/-}$males were used in the control group, because they did not show any obvious difference in the phenotypes. Cauda epididymides from control males $(N=6,25.1 \pm 6.4$ weeks old) and $\mathrm{Bscl}^{-/-}$males ( $N=9,24.0 \pm 5.1$ weeks old) were dissected and prepared for sperm counting as described above. Meanwhile, the number of motile sperm from 
each preparation was also determined. Sperm motility was expressed as the percentage of motile sperm. The sperm number in the uterine flushing from each of the females mated with a subset of males in the fertility test was also counted using a hemocytometer.

Testis and rete testis histology and spermatogenesis staging. Testes from Bscl2 ${ }^{+/+}$and Bscl2 $/$- males at PND15, PND35, and 3-6 months old, as well as testes together with rete testis and epididymis from 6-month-old males were fixed in Bouin's solution (Ricca Chemical Company, Arlington, TX, USA) for $24 \mathrm{~h}$. They were then kept in $70 \%$ ethanol until embedded in paraffin for sectioning. Each testis was cut perpendicular to the long axis of the seminiferous tubules. Paraffin sections $(5 \mu \mathrm{m})$ were processed and stained with hematoxylin and eosin. ${ }^{21}$ $N=3-6$ for each time point and each genotype. To determine spermatogenesis stages, a representative $\times 20$ testis histology image with only cross-sectioned round seminiferous tubules from each adult mouse (3-6 months old) was analyzed. As spermatids in the $\mathrm{Bscl}^{-1-}$ seminiferous tubules were disorientated and prevented accurate staging, the following information was collected: the number of intact seminiferous tubules in each image, the number of seminiferous tubules without round spermatids (stage IX-XI), and the total number of round spermatids in all intact seminiferous tubules in each $\times 20$ image. Histology of rete testes was obtained by sectioning through the testis and rete testis, and stained with hematoxylin and eosin as described above.

Quantitative RT-PCR. Testes from wild-type C57BL/6J males at PND15 $(N=5)$ and 3-month-old mice $(N=3)$ were snap frozen on dry ice. Total RNA was extracted with Trizol (Life Technologies, Grand Island, NY, USA). Complementary DNA (cDNA) was transcribed using Superscript III reverse transcriptase (Life Technologies) with random primers as previously described. ${ }^{21,45,46}$ Quantitative PCR was performed in 384-well plates using SYBR-Green I intercalating dye on ABI 7900 (Applied Biosystems, Carlsbad, CA, USA). The mRNA expression levels of Bscl2 were determined using gene-specific primers from different exons (Integrated DNA Technology, Coralville, IA, USA), mBscl2e3F: 5'-GTGCACTTCCACTA CAGGAC-3' and mBscl2e6R: 5'-CTCCAGTTGTTGGCACATAC-3'. Gapdh (glyceraldehyde-3-phosphate dehydrogenase) was used as a loading control and Hprt1 (hypoxanthine phosphoribosyltransferase 1), another housekeeping gene, served as a second control as previously described. ${ }^{47}$ For quantification of Prm1 and Prm2, total RNA was extracted from 3-month-old $\mathrm{Bscl}^{+/+}$and $\mathrm{Bscl}^{-/-}$males $(\mathrm{N}=5)$ with Trizol (Life Technologies) and CDNA was transcribed as described above. Quantitative PCR was performed using Ssoadvanced SYBR Green Supermix (BioRad, Hercules, CA, USA) on CFX384 Touch Real-Time PCR Detection System (Bio-Rad). Gene-specific primers (Integrated DNA Technology) were designed as reported previously: ${ }^{48} \mathrm{mPrm} 1 \mathrm{e} 2 \mathrm{~F}: 5^{\prime}$-AGGTGTAAAAATACTAGATGCACAGAATAG-3', mPrm1e2R: 5'-TTCAAGATGTGGCGAGATGCT-3'; and mPrm2e2F: 5'-GAATAGT CACCTGCCCAAGCA-3', mPrm2e2R: 5'-GCAGCTCAGGGCTCAGACA-3'. Gapdh and $H$ prt1 were used as control as described above.

In situ hybridization. Bscl2 sense and antisense cRNA probes were synthesized as previously described, ${ }^{49}$ except that the template for cRNA probe synthesis was amplified from mBscl2 cDNA using primers mBscl2e3F and $\mathrm{mBscl2e6R}$ for PCR. The amplified Bscl2 cDNA fragment was recovered from agarose gel and cloned into pGEM-T Easy Vector (Promega, Madison, WI, USA). The recombinant plasmid was amplified with T7 and SP6 primers to produce templates for labeling antisense and sense probes, respectively. Testes from wildtype males at PND15, PND20, PND28, PND35, 3 months old, and 7 months old were snap frozen on dry ice and kept at $-80^{\circ} \mathrm{C}$. Frozen testis cross-sections $(10 \mu \mathrm{m})$ were cut and processed. Testis sections were mounted on (3-aminopropyl) triethoxy silane-coated slides, fixed in $4 \%$ paraformaldehyde in diethylpyrocarbonate (DEPC)-treated $\mathrm{H}_{2} \mathrm{O}$ for $1 \mathrm{~h}$ at room temperature. Sections were washed twice with $1 \times$ PBS in DEPC $\mathrm{H}_{2} \mathrm{O}$ for $5 \mathrm{~min}$, treated with $1 \%$ Triton $\mathrm{X}-100$ for $20 \mathrm{~min}$, then washed three times in $1 \times$ PBS for 5 min each. Sections were prehybridized in $50 \%$ formaldehyde $/ 5 \times$ saline-sodium citrate (SSC) buffer at room temperature for $15 \mathrm{~min}$ and then hybridized with digoxigenin-labeled sense (as a negative control) or antisense riboprobes for $16-20 \mathrm{~h}$. Sections were next washed in $5 \times$ SSC, $50 \%$ formamide at $55{ }^{\circ} \mathrm{C}$ for $15 \mathrm{~min} ; 2 \times \mathrm{SSC}, 50 \%$ formamide at $55^{\circ} \mathrm{C}$ for $30 \mathrm{~min} ; 0.2 \times$ SSC, $50 \%$ formamide twice at $55^{\circ} \mathrm{C}$ for $30 \mathrm{~min}$ each; and $0.2 \times$ SSC at room temperature for $5 \mathrm{~min}$, then washed in buffer $\mathrm{B} 1(1 \mathrm{M}$ Tris- $\mathrm{HCl} \mathrm{pH7.5,2.5} \mathrm{M} \mathrm{NaCl}$ in $\mathrm{ddH}_{2} \mathrm{O}$ ) for $5 \mathrm{~min}$ at room temperature. Slides were incubated with $1 \%$ blocking agent (Boehringer, Mannheim, Germany) in buffer B1 at room temperature for $1 \mathrm{~h}$. Slides were next incubated with 1:2000 Anti-Digoxigenin-AP, fab fragment
(Roche Applied Science, Indianapolis, IN, USA) in $1 \%$ blocking reagent at $4{ }^{\circ} \mathrm{C}$ overnight. After being washed three times in buffer $\mathrm{B} 1$ for $5 \mathrm{~min}$ each, slides were washed in buffer $\mathrm{B} 3\left(1 \mathrm{M}\right.$ Tris- $\mathrm{HCl} \mathrm{pH} 9.5,0.5 \mathrm{M} \mathrm{MgCl}_{2}, 2.5 \mathrm{M} \mathrm{NaCl}$ in $\left.\mathrm{ddH}_{2} \mathrm{O}\right)$ for $5 \mathrm{~min}$ at room temperature. The hybridization was visualized with substrates nitroblue tetrazolium and 5-bromo-4-chloro-3-indolyl phosphate (Roche Applied Science) in buffer B3, and endogenous alkaline phosphatase activity was inhibited with $2 \mathrm{mM}$ Levamisole (Sigma-Aldrich, St Louis, MO, USA) added to the substrate solution. Some sections were counterstained with methyl green as previously described. $^{49,50}$ Testes from at least three different mice were examined for each time point.

Immunohistochemistry. Paraffin sections $(5 \mu \mathrm{m})$ were used to detect seipin expression in the testes from PND15, PND20, PND35, and 3-month-old wild-type mice using our customized rabbit polyclonal anti-seipin antibody $(1: 1000,2.21 \mu \mathrm{g} / \mathrm{ml}$, Thermo Fisher Scientific, Waltham, MA, USA), which was raised against the C-terminal 17 amino acids of mouse seipin as previously described. ${ }^{51}$ Briefly, testis sections were rehydrated, subjected to antigen retrieval in $10 \mathrm{mM}$ sodium citrate $\mathrm{pH}$ 6) for $20 \mathrm{~min}$ in a microwave, and then washed in $1 \times \mathrm{PBS}$ and $\mathrm{ddH}_{2} \mathrm{O}$ for $5 \mathrm{~min}$ each. All steps were carried out at room temperature unless specified. Endogenous horseradish peroxidase (HRP) was blocked with $3 \% \mathrm{H}_{2} \mathrm{O}_{2}$ in methanol for 10 min and then washed in $\mathrm{ddH}_{2} \mathrm{O}$ and $1 \times$ PBS for $5 \mathrm{~min}$, respectively. Nonspecific staining was blocked with $10 \%$ goat serum for $1 \mathrm{~h}$. Sections were then incubated with rabbit anti-seipin overnight at $4{ }^{\circ} \mathrm{C}$. Sections were washed in $1 x$ PBS for $5 \mathrm{~min}$, incubated with biotinylated goat anti-rabbit lgG $(1: 200,7.5 \mu \mathrm{g} / \mathrm{ml}$, BA-1000, Vector Laboratories, Burlingame, CA, USA) in $1 \%$ BSA for 30 min. After washing three times with $1 \times$ PBS for 5 min each, sections were incubated with HRP streptavidin (SA-5004, Vector Laboratories) for 30 min and then washed three times in $1 \times$ PBS for $5 \mathrm{~min}$ each. After development with 3,3' diaminobenzidine tetrahydrochloride $\left(0.03 \%-0.05 \%\right.$ in $0.05 \mathrm{M}$ Tris- $\left.\mathrm{HCl} \mathrm{pH} 7.6,0.01 \%-0.03 \% \mathrm{H}_{2} \mathrm{O}_{2}\right)$ for 5-10 min, sections were counterstained with hematoxylin, dehydrated, cleared, and mounted. Cleaved caspase-3 was detected in testes from 4- to 6-month-old $\mathrm{BsCl}^{+/+}$males $(N=3)$ and $B s c l 2^{-1-}$ males $(N=4)$ using rabbit anti-cleaved caspase-3 (Asp175) antibody (1:300 dilution, Cell Signaling Technology, Danvers, MA, USA) in paraffin sections. Two types of negative control were used: sections from 3-month-old $\mathrm{Bscl}^{-1-}$ males incubated with anti-seipin antibody, and sections from 3-month-old $\mathrm{Bscl}^{+/+}$males incubated with normal rabbit IgG $(1: 1000$, Santa Cruz Biotechnology, Dallas, TX, USA). All other procedures were the same as described above. Testes from at least three different mice were used.

In situ end-labeling plus. ISEL ${ }^{+}$detects DNA breaks. ${ }^{20,21}$ One testis each from 3-4-month-old $\mathrm{BsCl}^{+++}$and $B s c l 2^{-1-}$ males $(N=5)$ was analyzed. Five consecutive testis sections $(10 \mu \mathrm{m})$ separated by $200 \mu \mathrm{m}$ each from each testis were processed for ISEL ${ }^{+}$labeling as previously described. ${ }^{20,21}$ All 50 sections (10 mice, 5 sections each) were processed at the same run and low magnification $(\times 4)$ images were taken at the same setting. Only the entire area covered with testis section from each image was quantified using ImageJ (National Institutes of Health, Bethesda, MD, USA) to determine the stained area. ISEL labeling was expressed as ISEL $^{+}$labeled area $\times 100 /$ total area analyzed. The average of all five sections was used to represent each sample for statistical analysis. Testis sections from another set of 3- to 4-month-old mice $(N=3)$ were processed for $\mathrm{ISEL}^{+}$labeling and counterstained with DAPI as previously described. ${ }^{21}$

Annexin V staining. Testes from 5-month-old control $(N=3)$ and $B s c / 2^{-1-}$ $(N=4)$ males were decapsulated and the seminiferous tubules were incubated in $0.25 \%$ trypsin at $37^{\circ} \mathrm{C}$ for $10 \mathrm{~min}$. The trypsin solution was removed and a small piece of the seminiferous tubules was minced in annexin- $V$ binding buffer and subsequently incubated with annexin V (Annexin V-FITC Apoptosis Kit, BioVision, Milpitas, CA, USA) at room temperature for $5 \mathrm{~min}$ in the dark. The cells were counterstained with DAPI. At least 100 round spermatids from each male were examined. The percentage of annexin V-positive round spermatids was calculated.

Mitotracker staining. One cauda epididymis from each of the control mice $(N=3)$ and two cauda epididymides from each of the $B s c / 2^{-1-}$ mice $(N=4)$ used for annexin $\mathrm{V}$ staining above were collected for staining the mitochondria of sperm. Each sample was minced in $1 \mathrm{ml}$ (for control) or $0.2 \mathrm{ml}$ (for Bscl2 ${ }^{-1-}$ ) $1 \times$ PBS in a $1.5-\mathrm{ml}$ microcentrifuge tube and shaken at $37^{\circ} \mathrm{C} / 5 \% \mathrm{CO}_{2}$ for $5 \mathrm{~min}$. Therefore, the $\mathrm{Bscl}^{-1}$ - samples were $10 \times$ concentrated in order to get sufficient sperm density due to low sperm count in the $B s c / 2^{-1-}$ male. Mitotracker stock solution (MitoTracker Deep Red FM, Life Technologies) was added into the sperm 
suspensions to a final concentration of $10 \mu \mathrm{M}$ and incubated in the dark at $37^{\circ} \mathrm{C}$ for $10 \mathrm{~min}$. One drop of sperm suspension from each sample was added on a slide, air dried, and counterstained with DAPI.

Immunofluorescence. Frozen testis sections $(10 \mu \mathrm{m})$ from 3- to 4-month-old $\mathrm{Bscl}^{+/+}$and $\mathrm{Bscl}^{-/-}$males $(\mathrm{N}=4)$ were used for detecting the expression of vimentin, PRM1, and PRM2 following the procedure as described previously. ${ }^{49}$ Sections were incubated with vimentin antibody (1:50 dilution, sc-373717, Santa Cruz Biotechnology) or PRM1 antibody (1:100 dilution, $21 \mu \mathrm{g} / \mathrm{ml}$, Hup $1 \mathrm{~N}$, Briar Patch Biosciences, Livermore, CA, USA), or PRM2 antibody (1: 100 dilution, $21 \mu \mathrm{g} / \mathrm{ml}$, Hup2B, Briar Patch Biosciences) overnight at $4{ }^{\circ} \mathrm{C}$. Vimentin, PRM1, and PRM2 signals were detected by incubating with Alexa Fluor 568 goat anti-mouse antibody (1:200 dilution, Life Technologies) for 30-60 min at room temperature. Testis sections were counterstained and mounted in DAPI-containing Vectashield (Vector Laboratories). Two types of negative control were used: sections of 3-monthold $B s c / 2^{+/+}$males incubated with mouse lgG (1: 100, Santa Cruz Biotechnology) or without any primary antibody. All other procedures were the same as described above. In addition, PRM1 and PRM2 were also detected in the sperm spreads from $\mathrm{Bscl}^{+/+}$and $\mathrm{Bscl}^{-1-}$ males (4 months old, $\mathrm{N}=3$ ) using the same condition as for testis sections.

Acrosome labeling. Acrosomes were highlighted with Alexa Fluor 488conjugated PNA. ${ }^{52}$ Briefly, fixed frozen testis sections from three young adult male mice in each group were treated with $0.3 \%$ Triton for $10 \mathrm{~min}$ at room temperature. Subsequently, they were incubated with $10 \mu \mathrm{g} / \mathrm{ml}$ PNA in $1 \%$ BSA in $1 \times$ PBS for $1 \mathrm{~h}$ at room temperature, counterstained with DAPI, and mounted.

Spermatogenic surface preparations for chromatin analysis. Testes from $\mathrm{Bscl}^{+/+}$and $\mathrm{Bscl} 2^{-1-}$ males (4 months old, $N=3$ ) were dissected and the tunica albuginea was removed to expose individual seminiferous tubules in $1 \times$ PBS. The seminiferous tubules were immediately processed for cytological analysis of marker proteins of meiotic chromosome synapsis as described previously. ${ }^{53}$ Hypotonic treatment was used to aid in the dissociation of germ cells from the seminiferous tubules and to facilitate meiotic chromosome spreading and subsequent marker protein analysis by chromatin decondensation. Briefly, seminiferous tubules were incubated in a sodium citrate solution $(30 \mathrm{mM}$ Tris, $50 \mathrm{mM}$ sucrose, $17 \mathrm{mM}$ trisodium citrate, $5 \mathrm{~mm}$ EDTA pH 8.2) for 25 to $35 \mathrm{~min}$ at room temperature. Following dissociation, drops of cell suspension were applied to wet glass slides containing 2\% paraformaldehyde (Electron Microscopy Services, Hatfield, PA, USA) and $0.15 \%$ Triton X-100 (Bio-Rad) in $\mathrm{H}_{2} \mathrm{O}$, to facilitate nuclear protein cross-linking. Slides were allowed to air dry and then stored at $-80^{\circ} \mathrm{C}$ until immunochemical analysis.

Immunofluorescence of spermatogenic surface spreads. Meiotic prophase I staging and the degree of chromosome synapsis in $\mathrm{Bscl}^{+/+}$and $B s c l 2^{-1-}$ spermatocytes were determined by co-immunochemical detection of the SYCP1 and SYCP3 using polyclonal mouse anti-SYCP3 (Abcam, Cambridge, MA, USA) and polyclonal rabbit anti-SYCP1 (Abcam) antibodies at a 1:500 dilution in dilution buffer (1 mg/ml BSA (Sigma) in $1 \times$ PBS, $0.01 \%$ Triton X-100). Following overnight incubation at $4{ }^{\circ} \mathrm{C}$ and repeated wash steps in dilution buffer, an Alexa Fluor 555 goat anti-mouse (Life Technologies) and an Alexa Fluor 488 goat antirabbit secondary antibody were applied at a dilution of $1: 1000$ for $1 \mathrm{~h}$ at room temperature. The male germ cells were then counterstained and mounted in DAPIcontaining Vectashield (Vector Laboratories). Similarly, the subnuclear localization of pericentric heterochromatin domains was detected using a rabbit anti-H3K9me3 antibody $(1: 400$, Upstate, Charlottesville, VA, USA). Immunofluorescence and chromatin configurations were visualized using a Leica DMRE fluorescence microscope (Buffalo Grove, IL, USA), and images were captured using a Leica DFC $350 \mathrm{~F}$ CCD camera. At least 100 randomly selected round spermatids from each sample were examined for the presence of chromocenter fragmentation. At least 100 randomly selected elongating spermatids and sperm from each sample were examined for the presence of chromatin vacuoles. The percentages of round spermatids with chromocenter fragmentation, as well as elongating spermatids and sperm with chromatin vacuoles, were quantified.

Statistical analyses. Data are presented as mean \pm S.D. Wilcoxon rank sum test was used for plugging latency. The $\chi^{2}$-test was used for pregnancy rate and plugging rate. Two-tailed unequal variance Student's $t$-test was used for the rest of the parameters. For the parameters with percentages, Student's t-test was performed after arcsine transformation. The significance level was set at $P<0.05$.

\section{Conflict of Interest}

The authors declare no conflict of interest.

Acknowledgements. We thank the Department of Pathology in the College of Veterinary Medicine, University of Georgia, for access to the imaging system; Dr James N. Moore in the Department of Large Animal Medicine for access to the ABI 7900 Realtime PCR machine; Dr Qien Yang at Northwest Plateau Institute of Biology, The Chinese Academy of Sciences, for insightful suggestions; the Office of the Vice President for Research, Interdisciplinary Toxicology Program, and Department of Physiology and Pharmacology at the University of Georgia, the National Institutes of Health (NIH R15HD066301 and NIH R01HD065939 (co-funded by ORWH and NICHD) to XY and NIH 2R01HD042740 to RDLF); and the Georgia Cancer Coalition (to RDLF) for financial support.

1. Magre J, Delepine M, Khallouf E, Gedde-Dahl Jr T, Van Maldergem L, Sobel E et al. Identification of the gene altered in Berardinelli-Seip congenital lipodystrophy on chromosome 11q13. Nat Genet 2001; 28: 365-370.

2. Cui $X$, Wang $Y$, Tang $Y$, Liu $Y$, Zhao L, Deng J et al. Seipin ablation in mice results in severe generalized lipodystrophy. Hum Mol Genet 2011; 20: 3022-3030.

3. Prieur X, Dollet L, Takahashi M, Nemani M, Pillot B, Le May C et al. Thiazolidinediones partially reverse the metabolic disturbances observed in Bscl2/seipin-deficient mice. Diabetologia 2013; 56: 1813-1825.

4. Lundin C, Nordstrom R, Wagner K, Windpassinger C, Andersson $\mathrm{H}$, von Heijne $\mathrm{G}$ et al. Membrane topology of the human seipin protein. FEBS Lett 2006; 580: 2281-2284.

5. Sim MF, Talukder MU, Dennis RJ, Edwardson JM, Rochford JJ. Analyzing the functions and structure of the human lipodystrophy protein seipin. Methods Enzymol 2014; 537: 161-175.

6. Szymanski KM, Binns D, Bartz R, Grishin NV, Li WP, Agarwal AK et al. The lipodystrophy protein seipin is found at endoplasmic reticulum lipid droplet junctions and is important for droplet morphology. Proc Natl Acad Sci USA 2007; 104: 20890-20895.

7. Bi J, Wang W, Liu Z, Huang X, Jiang Q, Liu G et al. Seipin promotes adipose tissue fat storage through the ER Ca(2+)-ATPase SERCA. Cell Metab 2014; 19: 861-871.

8. Chen W, Chang B, Saha P, Hartig SM, Li L, Reddy VT et al. Berardinelli-seip congenital lipodystrophy $2 /$ seipin is a cell-autonomous regulator of lipolysis essential for adipocyte differentiation. Mol Cell Biol 2012; 32: 1099-1111.

9. Agarwal AK, Garg A. Congenital generalized lipodystrophy: significance of triglyceride biosynthetic pathways. Trends Endocrinol Metab 2003; 14: 214-221.

10. Jiang M, Gao M, Wu C, He H, Guo X, Zhou Z et al. Lack of testicular seipin causes teratozoospermia syndrome in men. Proc Natl Acad Sci USA 2014; 111: 7054-7059.

11. Cartwright BR, Goodman JM. Seipin: from human disease to molecular mechanism. J Lipid Res 2012; 53: 1042-1055.

12. Dollet L, Magre J, Cariou B, Prieur X. Function of seipin: new insights from Bscl2/seipin knockout mouse models. Biochimie 2014; 96: 166-172.

13. Rodriguez I, Ody C, Araki K, Garcia I, Vassalli P. An early and massive wave of germinal cell apoptosis is required for the development of functional spermatogenesis. EMBO J 1997; 16: 2262-2270.

14. Blanco-Rodriguez J, Martinez-Garcia C. Spontaneous germ cell death in the testis of the adult rat takes the form of apoptosis: re-evaluation of cell types that exhibit the ability to die during spermatogenesis. Cell Prolif 1996; 29: 13-31.

15. Shaha C, Tripathi R, Mishra DP. Male germ cell apoptosis: regulation and biology. Philos Trans R Soc Lond B Biol Sci 2010; 365: 1501-1515.

16. Hendriks G, Atallah M, Raamsman M, Morolli B, van der Putten $\mathrm{H}$, Jaadar $\mathrm{H}$ et al. Sensitive DsRed fluorescence-based reporter cell systems for genotoxicity and oxidative stress assessment. Mutat Res 2011; 709-710: 49-59.

17. Hendriks G, Atallah M, Morolli B, Calleja F, Ras-Verloop N, Huijskens I et al. The ToxTracker assay: novel GFP reporter systems that provide mechanistic insight into the genotoxic properties of chemicals. Toxicol Sci 2012; 125: 285-298.

18. Lightfoot RJ, Restall BJ. Effects of site of insemination, sperm motility and genital tract contractions on transport of spermatozoa in the ewe. J Reprod Fertil 1971; 26: 1-13.

19. Bellve AR, Cavicchia JC, Millette CF, O'Brien DA, Bhatnagar YM, Dym M. Spermatogenic cells of the prepuberal mouse. Isolation and morphological characterization. J Cell Biol 1977; 74: $68-85$.

20. Blaschke AJ, Staley K, Chun J. Widespread programmed cell death in proliferative and postmitotic regions of the fetal cerebral cortex. Development 1996; 122: 1165-1174.

21. Ye X, Skinner MK, Kennedy G, Chun J. Age-dependent loss of sperm production in mice via impaired lysophosphatidic acid signaling. Biol Reprod 2008; 79: 328-336.

22. Burgoyne PS, Mahadevaiah SK, Turner JM. The consequences of asynapsis for mammalian meiosis. Nat Rev Genet 2009; 10: 207-216.

23. Winters T, McNicoll F, Jessberger R. Meiotic cohesin STAG3 is required for chromosome axis formation and sister chromatid cohesion. EMBO J 2014; 33: 1256-1270. 
24. Kim Y, Fedoriw AM, Magnuson T. An essential role for a mammalian SWI/SNF chromatinremodeling complex during male meiosis. Development 2012; 139: 1133-1140.

25. Matoba S, Ogura A. Generation of functional oocytes and spermatids from fetal primordial germ cells after ectopic transplantation in adult mice. Biol Reprod 2011; 84: 631-638.

26. Vernet N, Mahadevaiah SK, Ojarikre OA, Longepied G, Prosser HM, Bradley A et al. The Y-encoded gene zfy2 acts to remove cells with unpaired chromosomes at the first meiotic metaphase in male mice. Curr Biol 2011; 21: 787-793.

27. Li W, Wu J, Kim SY, Zhao M, Hearn SA, Zhang MQ et al. Chd5 orchestrates chromatin remodelling during sperm development. Nat Commun 2014; 5: 3812

28. Namekawa SH, Park PJ, Zhang LF, Shima JE, McCarrey JR, Griswold MD et al. Postmeiotic sex chromatin in the male germline of mice. Curr Biol 2006; 16: 660-667.

29. Grewal SIS, Jia S. Heterochromatin revisited. Nat Rev Genet 2007; 8: 35-46.

30. Tanaka H, Baba T. Gene expression in spermiogenesis. Cell Mol Life Sci 2005; 62: 344-354.

31. Ravel C, Chantot-Bastaraud S, El Houate B, Berthaut I, Verstraete L, De Larouziere V et al. Mutations in the protamine 1 gene associated with male infertility. Mol Hum Reprod 2007; 13: 461-464.

32. Lee $\mathrm{K}$, Haugen $\mathrm{HS}$, Clegg $\mathrm{CH}$, Braun RE. Premature translation of protamine $1 \mathrm{mRNA}$ causes precocious nuclear condensation and arrests spermatid differentiation in mice. Proc Natl Acad Sci USA 1995; 92: 12451-12455.

33. Kleene KC. Patterns, mechanisms, and functions of translation regulation in mammalian spermatogenic cells. Cytogenet Genome Res 2003; 103: 217-224.

34. Russell LD, Lee IP, Ettlin R, Peterson RN. Development of the acrosome and alignment, elongation and entrenchment of spermatids in procarbazine-treated rats. Tissue Cell 1983; 15: 615-626.

35. Ruiz-Pesini E, Diez C, Lapena AC, Perez-Martos A, Montoya J, Alvarez E et al. Correlation of sperm motility with mitochondrial enzymatic activities. Clin Chem 1998; 44: 1616-1620.

36. Wang R, Sperry AO. PP1 forms an active complex with TLRR (Irrc67), a putative PP1 regulatory subunit, during the early stages of spermiogenesis in mice. PLoS One 2011; 6: e21767.

37. Berkovits BD, Wolgemuth DJ. The first bromodomain of the testis-specific double bromodomain protein Brdt is required for chromocenter organization that is modulated by genetic background. Dev Biol 2011; 360: 358-368.

38. Martianov I, Brancorsini S, Gansmuller A, Parvinen M, Davidson I, Sassone-Corsi P. Distinct functions of TBP and TLF/TRF2 during spermatogenesis: requirement of TLF for heterochromatic chromocenter formation in haploid round spermatids. Development 2002; 129: 945-955.

39. Martianov I, Fimia GM, Dierich A, Parvinen M, Sassone-Corsi P, Davidson I. Late arrest of spermiogenesis and germ cell apoptosis in mice lacking the TBP-like TLF/TRF2 gene. Mol Cell 2001; 7: 509-515.

40. Chung SS, Wang X, Wolgemuth DJ. Male sterility in mice lacking retinoic acid receptor alpha involves specific abnormalities in spermiogenesis. Differentiation 2005; 73: 188-198.

41. Boitrelle F, Albert M, Petit JM, Ferfouri F, Wainer R, Bergere M et al. Small human sperm vacuoles observed under high magnification are pocket-like nuclear concavities linked to chromatin condensation failure. Reprod Biomed Online 2013; 27: 201-211.

42. Baba T, Kashiwagi $Y$, Arimitsu N, Kogure T, Edo A, Maruyama T et al. Phosphatidic acid (PA)-preferring phospholipase A1 regulates mitochondrial dynamics. J Biol Chem 2014; 289: 11497-11511.
43. Manochantr S, Chiamchanya C, Sobhon P. Relationship between chromatin condensation DNA integrity and quality of ejaculated spermatozoa from infertile men. Andrologia 2012; 44: 187-199.

44. Bailly A, Gartner A. Germ cell apoptosis and DNA damage responses. Adv Exp Med Biol 2013; 757: 249-276.

45. Ye X, Herr DR, Diao H, Rivera R, Chun J. Unique uterine localization and regulation may differentiate LPA3 from other lysophospholipid receptors for its role in embryo implantation. Fertil Steril 2011; 95: 2107-2113.

46. Diao H, Aplin JD, Xiao S, Chun J, Li Z, Chen S et al. Altered spatiotemporal expression of collagen types I, III, IV, and VI in Lpar3-deficient peri-implantation mouse uterus. Biol Reprod 2011; 84: 255-265.

47. Diao H, Xiao S, Li R, Zhao F, Ye X. Distinct spatiotemporal expression of serine proteases prss 23 and prss 35 in periimplantation mouse uterus and dispensable function of prss 35 in fertility. PLoS One 2013; 8: e56757.

48. Hayashi S, Yang J, Christenson L, Yanagimachi R, Hecht NB. Mouse preimplantation embryos developed from oocytes injected with round spermatids or spermatozoa have similar but distinct patterns of early messenger RNA expression. Biol Reprod 2003; 69: 1170-1176.

49. Diao H, Xiao S, Howerth EW, Zhao F, Li R, Ard MB et al. Broad gap junction blocker carbenoxolone disrupts uterine preparation for embryo implantation in mice. Biol Reprod 2013; 89: 31

50. Diao H, Paria BC, Xiao S, Ye X. Temporal expression pattern of progesterone receptor in the uterine luminal epithelium suggests its requirement during early events of implantation. Fertil Steril 2011; 95: 2087-2093.

51. Li R, Zowalaty AE, Chen W, Dudley EA, Ye X. Segregated responses of mammary gland development and vaginal opening to prepubertal genistein exposure in Bscl2 female mice with lipodystrophy. Reprod Toxicol 2014; 54: 76-83.

52. Zheng J, Xia X, Ding H, Yan A, Hu S, Gong X et al. Erasure of the paternal transcription program during spermiogenesis: the first step in the reprogramming of sperm chromatin for zygotic development. Dev Dyn 2008; 237: 1463-1476.

53. Baumann C, Daly CM, McDonnell SM, Viveiros MM, De La Fuente R. Chromatin configuration and epigenetic landscape at the sex chromosome bivalent during equine spermatogenesis. Chromosoma 2011; 120: 227-244.

(c) (i) Cell Death and Disease is an open-access journal published by Nature Publishing Group. This work is licensed under a Creative Commons Attribution 4.0 International License. The images or other third party material in this article are included in the article's Creative Commons license, unless indicated otherwise in the credit line; if the material is not included under the Creative Commons license, users will need to obtain permission from the license holder to reproduce the material. To view a copy of this license, visit http://creativecommons.org/licenses/by/4.0/

Supplementary Information accompanies this paper on Cell Death and Disease website (http://www.nature.com/cddis) 